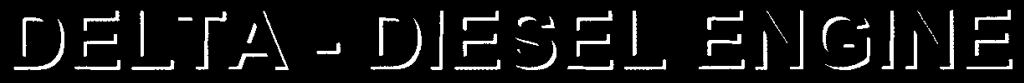

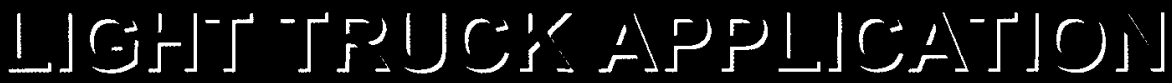

\section{Contract \#DE-FC05-97-OR22606}

\author{
Final Report
}

Prepared for:

Department of Energy

\author{
May 2003
}

DETAOIT DIESEL

corporation

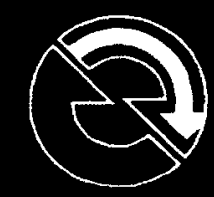

A DaimlerChrysler Powersystems Company 
TABLE OF CONTENTS

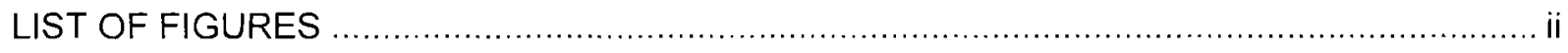

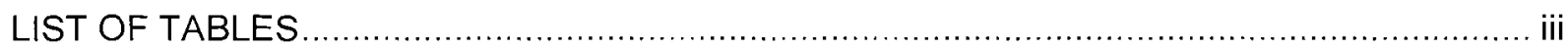

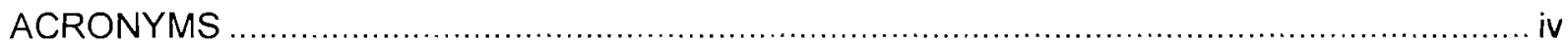

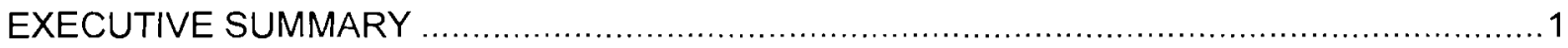

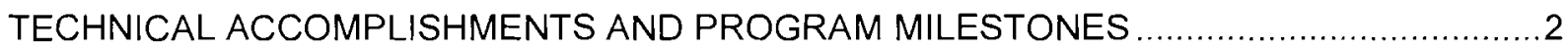

CHRONOLOGICAL PROGRESS OF THE DIESEL ENGINE LIGHT TRUCK APPLICATION

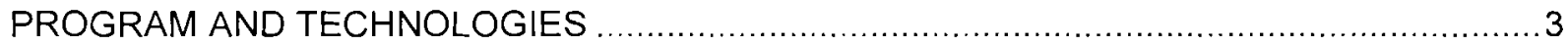

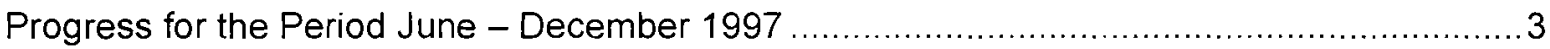

Progress for the Period January - March 1998 ...........................................................

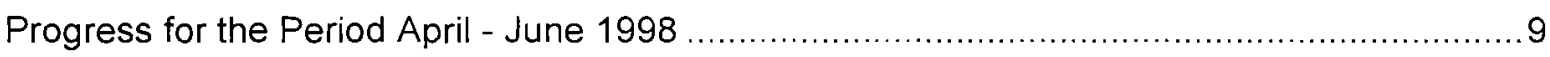

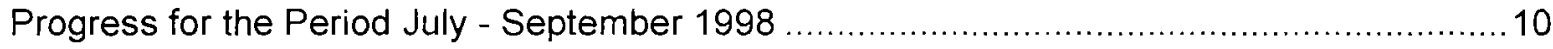

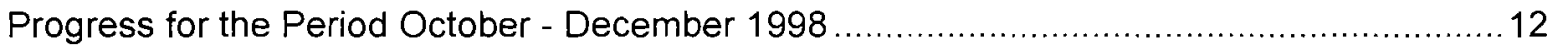

Progress for the Period January - March 1999 ............................................................... 13

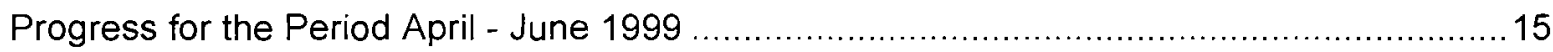

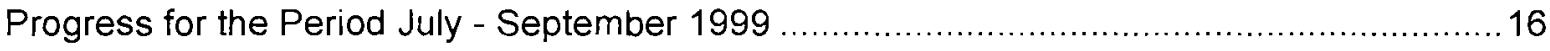

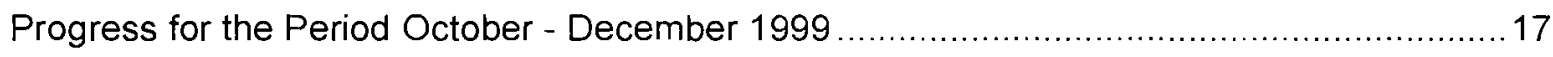

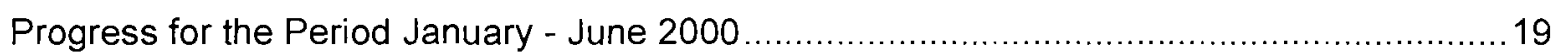

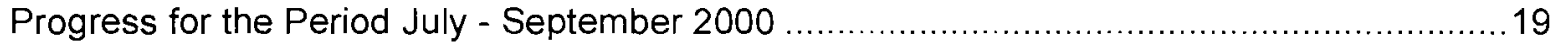

Progress for the Period October - December 2000 ....................................................20

Progress for the Period January - March 2001 ..............................................................24

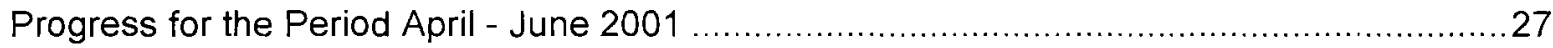

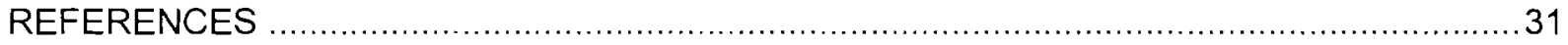




\section{LIST OF FIGURES}

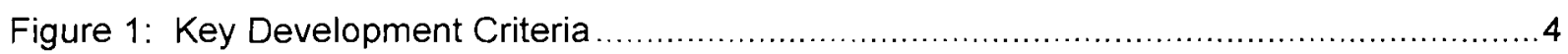

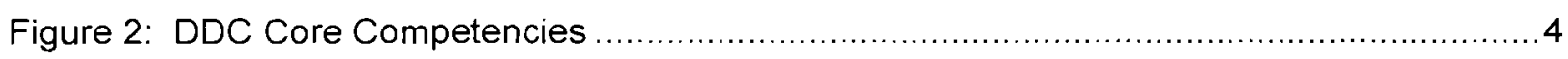

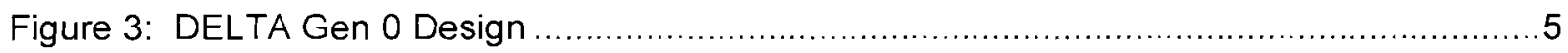

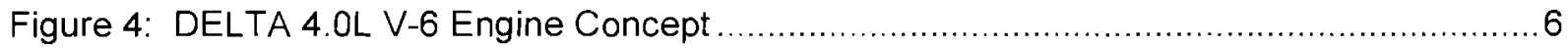

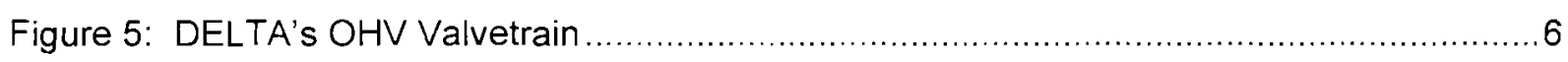

Figure 6: Valve Lash Adjuster Assemblies ..................................................................

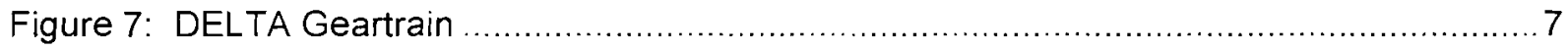

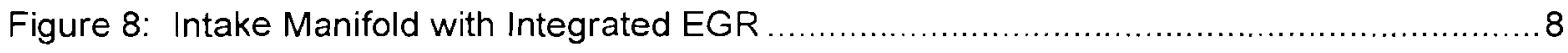

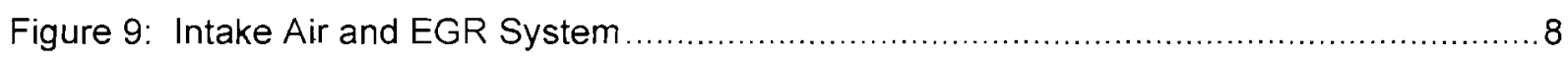

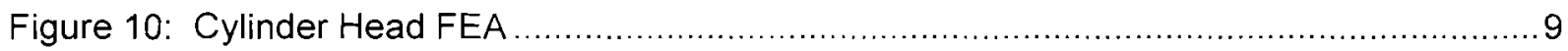

Figure 11: The First DELTA Gen 0 Engine Installed in a Test Cell .................................... 10

Figure 12: Durango Repowered with a DELTA Gen 0 Engine ......................................... 11

Figure 13: Preliminary Gen 0 Fuel Consumption Map .................................................... 11

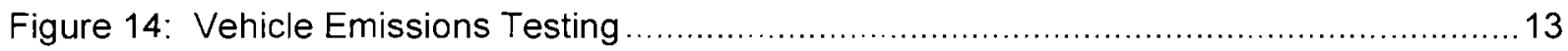

Figure 15: Twin VGT Gen 0 Configuration (Rear View of Engine) ....................................14

Figure 16: Durango Interior Noise Test Results................................................................ 15

Figure 17: Gen 1 Design Initiated to Resolve Gen 0 Issues ............................................17

Figure 18: DELTA Improved Performance Curve ......................................................... 18

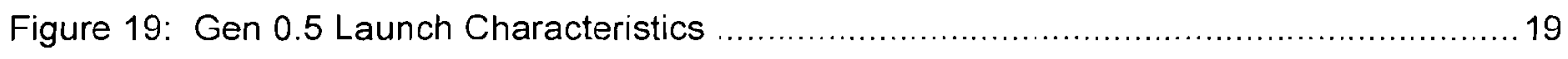

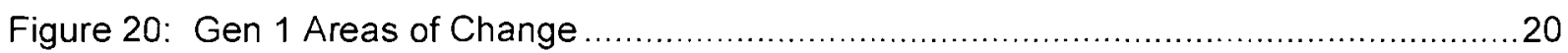

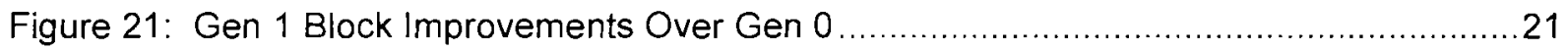

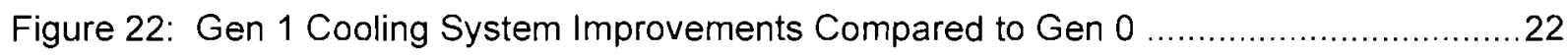

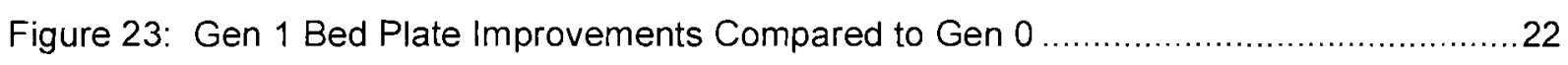

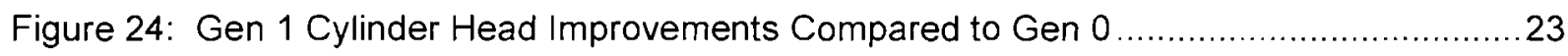

Figure 25: Improvements to the Intake Manifold over the Gen 0 Configuration ......................23

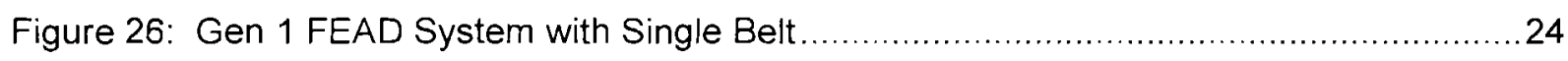

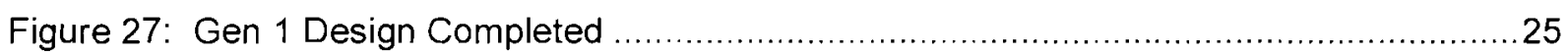

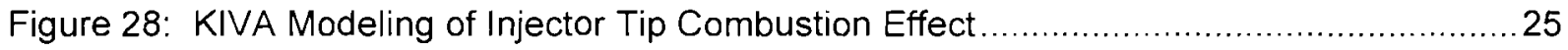

Figure 29: Gen 0.7 Cylinder Pressure vs. Speed/Load ..................................................26

Figure 30: Gen 0.7 Exhaust Temperature vs. Speed/Load ...........................................26

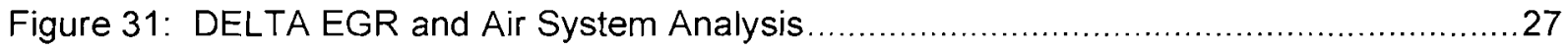

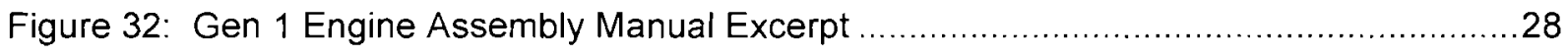

Figure 33: Gen 1 Engine Instrumentation Manual Excerpt .........................................29 
Figure 34: Gen 0.7 Durability Engine.

\section{LIST OF TABLES}

Table 1: Durango Performance vs. Engine. 12 


\section{ACRONYMS}

\begin{tabular}{|c|l|}
\hline All & Air Intake \\
\hline CLEAN Combustion $^{\odot}$ & Controlled Low Emission Aftertreatment Nurturing Combustion \\
\hline CFD & Computational Fluid Dynamics \\
\hline DDC & Detroit Diesel Corporation \\
\hline DEER & Diesel Engine Emissions Reduction \\
\hline DELTA & Diesel Engine Light Truck Application \\
\hline DOE & Department of Energy \\
\hline DPF & Diesel Particulate Filter \\
\hline EGR & Exhaust Gas Recirculation \\
\hline FEA & Finite Element Analysis \\
\hline FEAD & Front Engine Accessory Drives \\
\hline FTP & Federal Test Procedure \\
\hline Gen & Generation \\
\hline HP & High Pressure \\
\hline HSDI & High Speed Direct Injection \\
\hline LDT & Light Duty Truck \\
\hline MPG & Miles Per Gallon \\
\hline NOx & Nitrous Oxides \\
\hline NVH & Noise, Vibration and Harshness \\
\hline OEM & Original Equipment Manufacturer \\
\hline PM & Particulate Matter \\
\hline QFD & Quality Function Deployment \\
\hline SAE & Society of Automotive Engineers \\
\hline SFTP & Supplemental Federal Test Procedure \\
\hline SUV & Sports Utility Vehicle \\
\hline TPO & Turbine Outlet Pressure \\
\hline Valve Covered Orifice \\
\hline Variable Geometry Turbo \\
\hline
\end{tabular}




\section{DELTA}

\section{Diesel Engine Light Truck Application \\ End of Contract Report \\ DE-FC05-97-OR22606}

\section{EXECUTIVE SUMMARY}

This report is the final technical report of the Diesel Engine Light Truck Application (DELTA) program under contract DE-FC05-97-OR22606. During the course of this contract, Detroit Diesel Corporation analyzed, designed, tooled, developed and applied the "Proof of Concept" (Generation 0) 4.0L V-6 DELTA engine and designed the successor "Production Technology Demonstration" (Generation 1) 4.0L V-6 DELTA engine.

The objectives of DELTA Program contract DE-FC05-97-OR22606 were to:

- Demonstrate production-viable diesel engine technologies, specifically intended for the North American LDT and SUV markets

- Demonstrate emissions compliance with significant fuel economy advantages

With a clean sheet design, DDC produced the DELTA engine concept promising the following attributes:

- $30-50 \%$ improved fuel economy

- Low cost

- Good durability and reliability

- Acceptable noise, vibration and harshness (NVH)

- State-of-the-art features

- Even firing, 4 valves per cylinder

- High pressure common rail fuel system

- Electronically controlled

- Turbocharged, intercooled, cooled EGR

- Extremely low emissions via CLEAN Combustion` technology

To demonstrate the engine technology in the SUV market, DDC repowered a 1999 Dodge Durango with the DELTA Generation 0 engine. Fuel economy improvements were approximately $50 \%$ better than the gasoline engine replaced in the vehicle. 
TECHNICAL ACCOMPLISHMENTS AND PROGRAM MILESTONES

1997

- DOE DELTA funding awarded

- Gen 0 design initiated

1998

- Gen 0 tooled, built and running

- Durango repowered

1999

- Gen 1 design initiated

- Twin VGT Gen 0 developed

2000

- Gen 1 design and analysis

- CLEAN Combustion@ discovered

2001

- Gen 1 design completed 


\section{CHRONOLOGICAL PROGRESS OF THE DIESEL ENGINE LIGHT TRUCK APPLICATION PROGRAM AND TECHNOLOGIES}

In realizing the objectives of the DELTA Program of demonstrating production-viable diesel engine technologies and demonstrating emissions compliance for the North American LDT and SUV markets, significant technical accomplishments were attained. This report presents a chronological outline of the main technology building blocks from the conception phase in the second half of 1997 until the end of the contract on July 1, 2001.

\section{7}

\section{Progress for the Period June - December 1997}

The year 1997 witnessed the initiation of the DELTA program. A program management plan was put forward to define leading customer expectations, material cost, manufacturing quality and resource plan, supplier involvement and Government requirements. A technical study was also prepared to start identifying the DELTA engine concept and development approach, the technical expectations and challenges in the North American market.

DDC initiated the design process by conducting a Quality Function Deployment (QFD) analysis. This technique captured primary customer wants and, through an unbiased process, evaluated tradeoffs and dependencies. In the first phase, these parameters were reduced to technical system expectations. These formed the basis for the second QFD phase and ultimately the engine design process.

The key to this development process was defining the customer wants and prioritizing their importance to the engine design characteristics. Once established, discipline was used to maintain these guidelines throughout the development process.

The primary customer wants are identified in Figure 1. The impact on cost was the most highly ranked development criteria, followed by durability and driveability. Performance, fuel economy, noise and vibration were also highly ranked.

Evaluation of the primary customer wants, clearly indicated that the North American light truck market demanded a clean sheet development approach. DDC assessed its core competencies and recognized the DELTA engine must be a hybrid of several design philosophies. Refer to Figure 2.

High durability requirements and passenger car refinement necessitated a blend of European High Speed Direct Injection (HSDI) diesel technology, with North American heavy duty diesel experience. Recently developed technologies were necessary to address NVH and driveability expectations. Emissions reduction and aftertreatment technologies were still under development to comply with future emissions legislation. With that, the Gen 0 engine design was completed (Figure 3 ) and procurement initiated. 


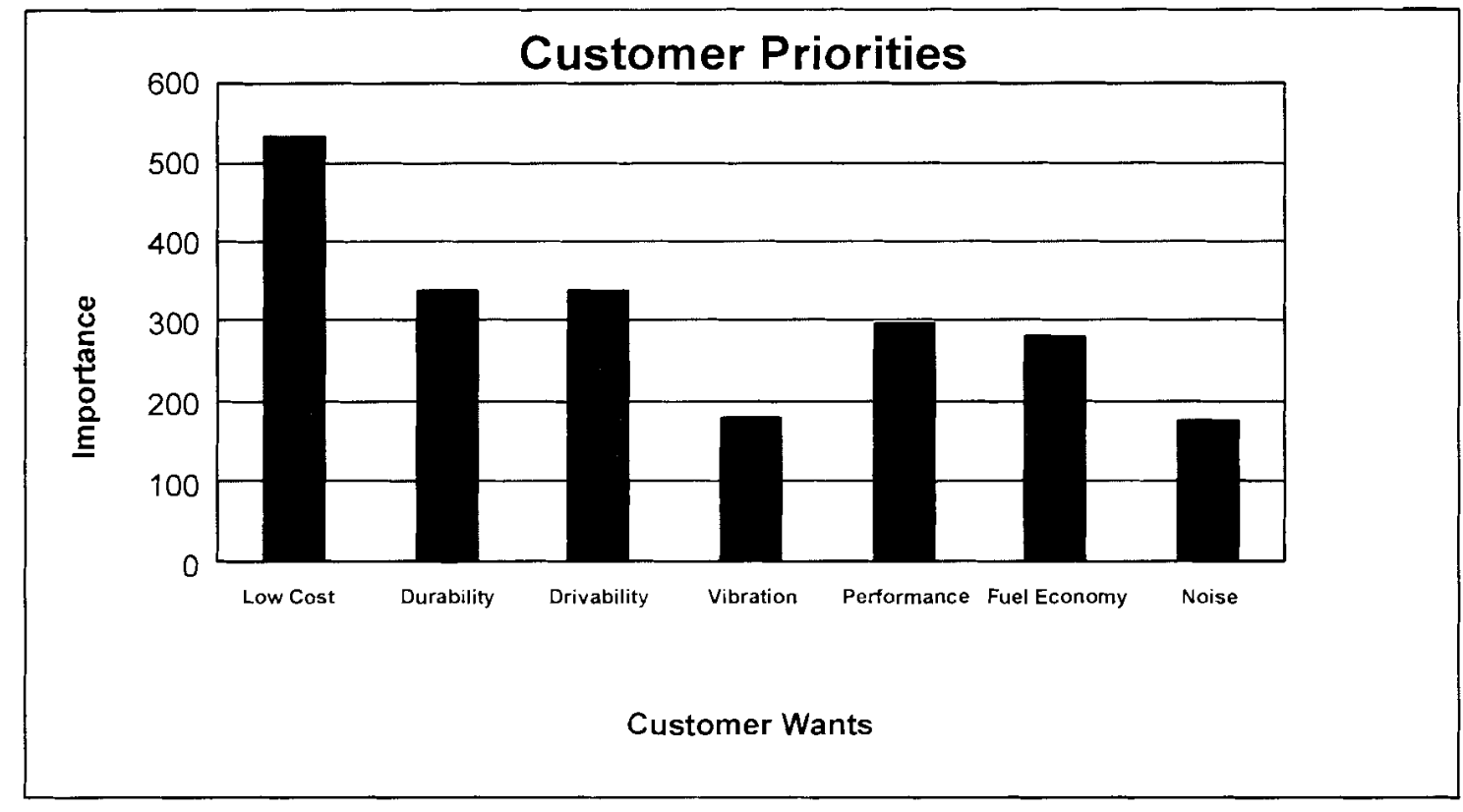

Figure 1: Key Development Criteria

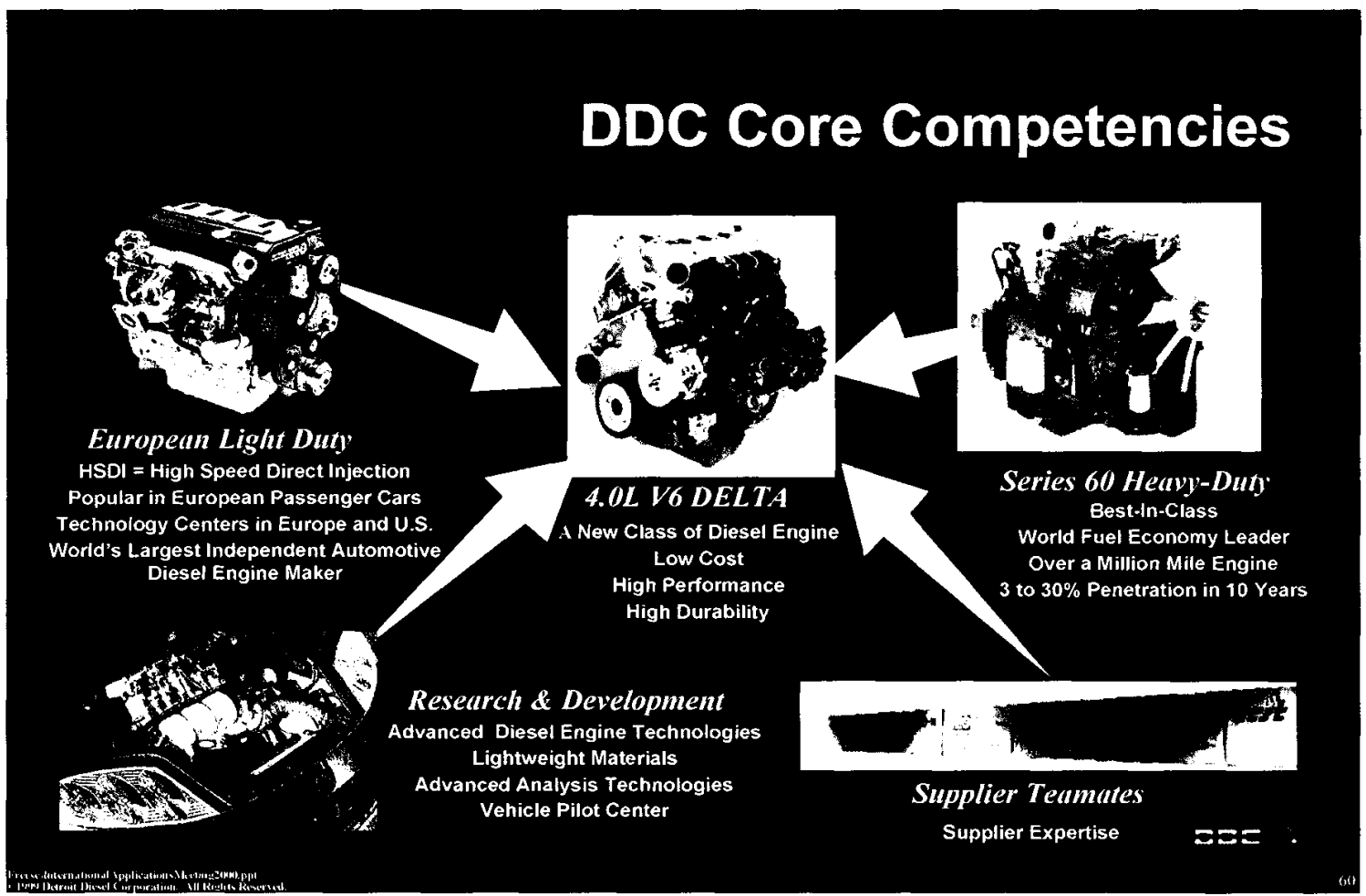

Figure 2: DDC Core Competencies 


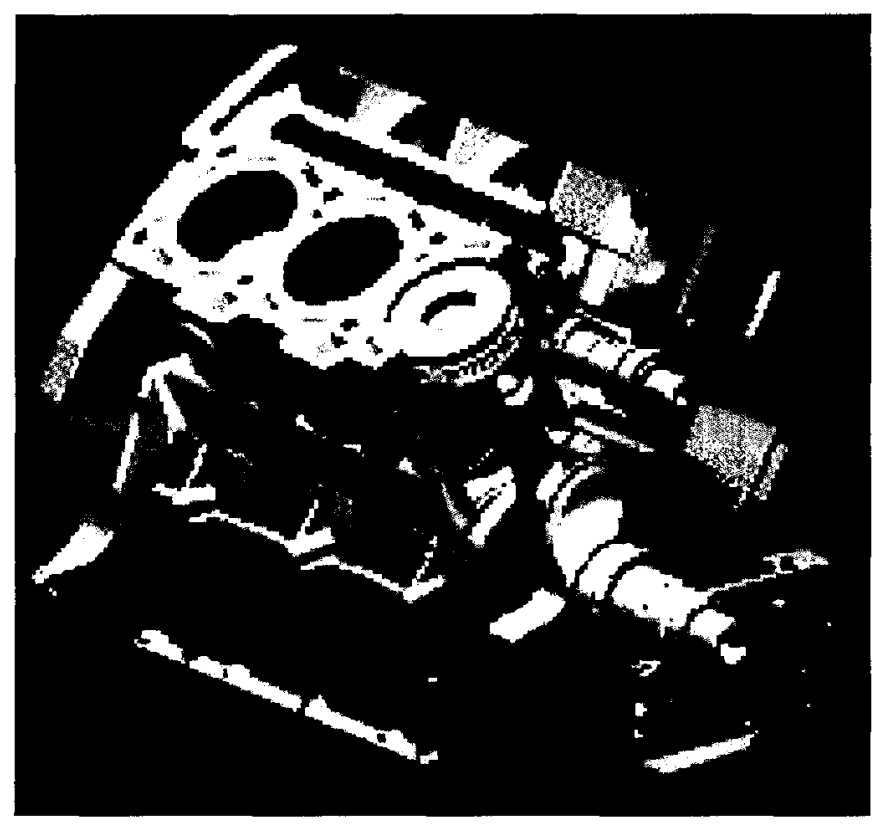

Figure 3: DELTA Gen 0 Design

\section{8}

Progress for the Period January - March 1998

DDC performed a market study through which technology benchmarking was completed and a 4.0L V-6 engine concept was defined as shown in Figure 4.

DELTA was designed to satisfy the key customer wants, while complying with required emissions and vehicle application constraints. NVH targets drove the design toward the 4.OL 60-degree V-6 architecture, rather than larger displacement and 90-degree bank angle alternatives. The 60-degree configuration permitted accessory packaging to the sides of the engine block. This approach reduced the overall engine length by 3.4 inches.

A 60-degree V-6 configuration also provided a significantly improved balance configuration with minimal cost. DELTA's common fuel rail was mounted centrally along the intake manifold. The 60 -degree bank angle minimized fuel line lengths, without requiring two fuel rails and expensive connecting lines, fittings and junction blocks.

Competitive noise appraisals and targets were identified, and combustion and thermodynamic simulations performed. Further progress included the selection of the fuel system and supplier, and the definition of the air system, port geometry, valve count and turbocharger. 


\subsection{L $60^{\circ} \mathrm{V}-6$ Diesel Engine}

- 4.0L V-6 Engine Architecture

- Even firing $60^{\circ}$ bank angle

- $92 \mathrm{~mm}$ bore X $101 \mathrm{~mm}$ stroke

- 4 valves per cylinder

- Common rail fuel system

- Central vertical injector

- Cast iron block, heads and bedplate

- Gear driven valvetrain

- Cooled EGR

- Wastegate turbocharger

- Intercooled
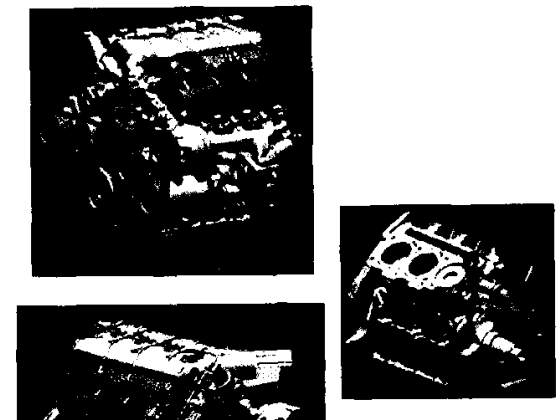

Figure 4: DELTA 4.0L V-6 Engine Concept

The following systems and their respective suppliers were also selected: valve train system (Figure 5), gear train system, piston and bearing supplier, as well as the block, head and bedplate material.

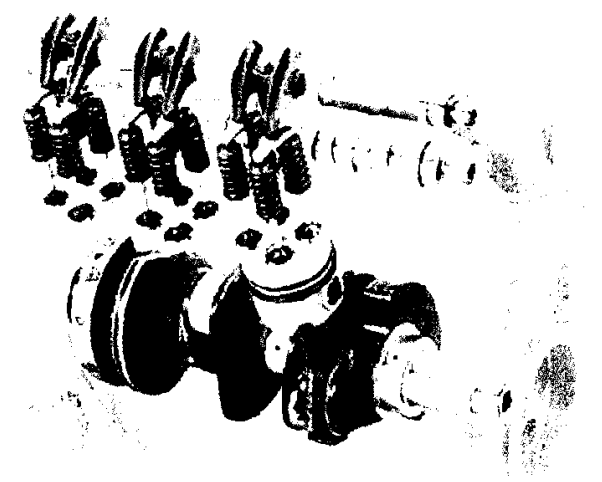

Figure 5: DELTA's OHV Valvetrain 
Hydraulic lash adjusters were used to eliminate valve lash adjustments, minimize valvetrain noise and avoid performance degradation. Refer to Figure 6.

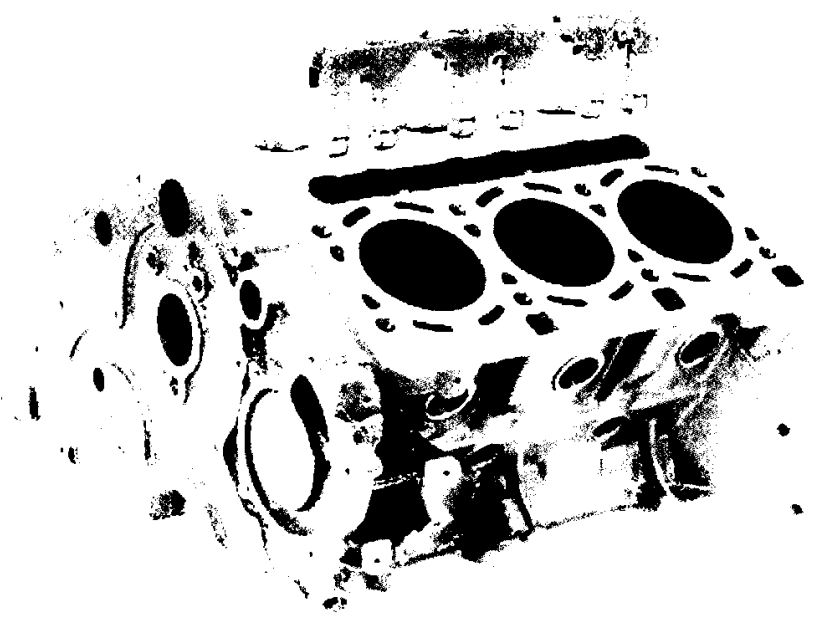

Figure 6: Valve Lash Adjuster Assemblies

DELTA used a spur gear-driven camshaft to avoid the maintenance and durability limitations of a timing chain. The compact geartrain was designed to minimize gear noise, using high contact ratio gears. Refer to Figure 7 .

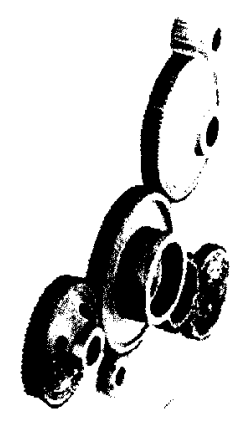

Figure 7: DELTA Geartrain 
DELTA was turbocharged and intercooled for emissions compliance, fuel economy and performance. A compact cooled Exhaust Gas Recirculation (EGR) system was integrated into the intake manifold. Refer to Figure 8.

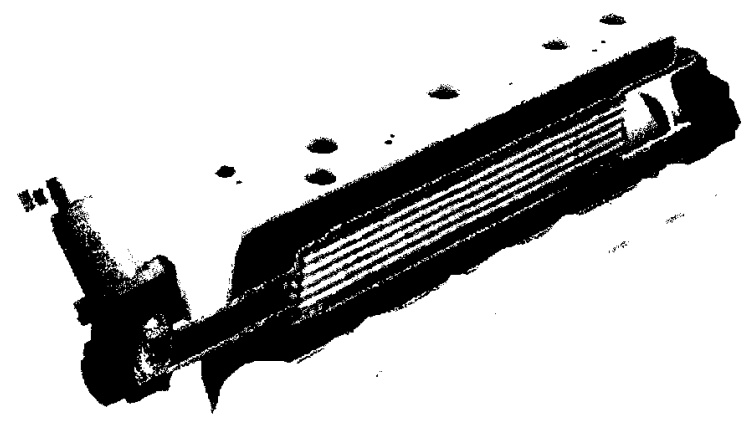

1

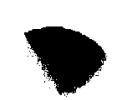

Figure 8: Intake Manifold with Integrated EGR

The exhaust manifolds included an extra connection to direct exhaust gases into the cylinder heads. EGR passages, which were cast into the cylinder heads, conducted EGR to the intake manifolds (Figure 9). The intake manifold provided a housing for the EGR valve and EGR cooler bundle.

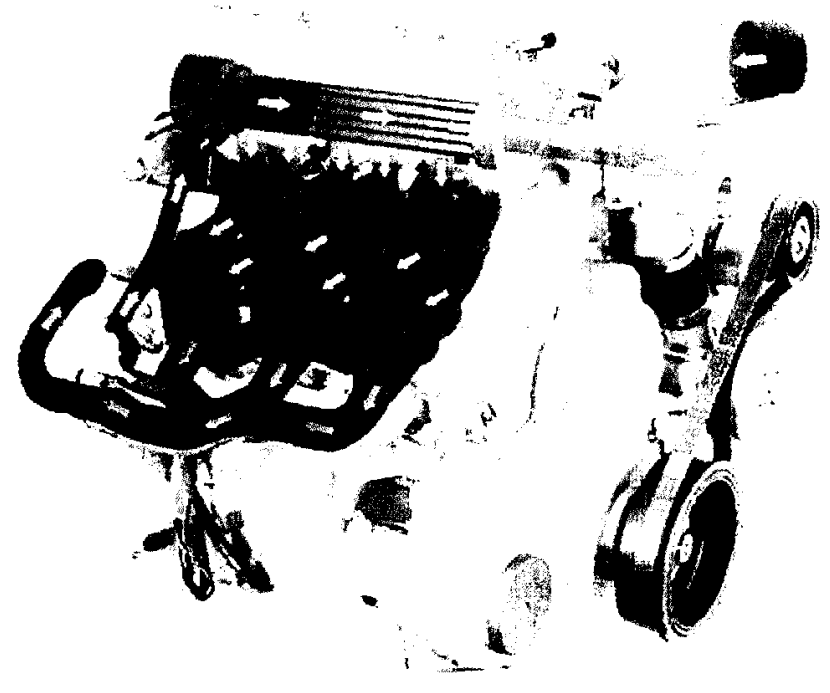

Figure 9: Intake Air and EGR System 


\section{Progress for the Period April - June 1998}

Analytical activities were the focus of this quarter. This included analysis of the following engine components and subsystems:

- Bearing load and oil film thickness

- Crankshaft finite element analysis (FEA)

- Connecting rod FEA

- Piston and ring system

- Valve train

- Gear train

- Cylinder block and head FEA (Figure 10)

- Oil and coolant flow

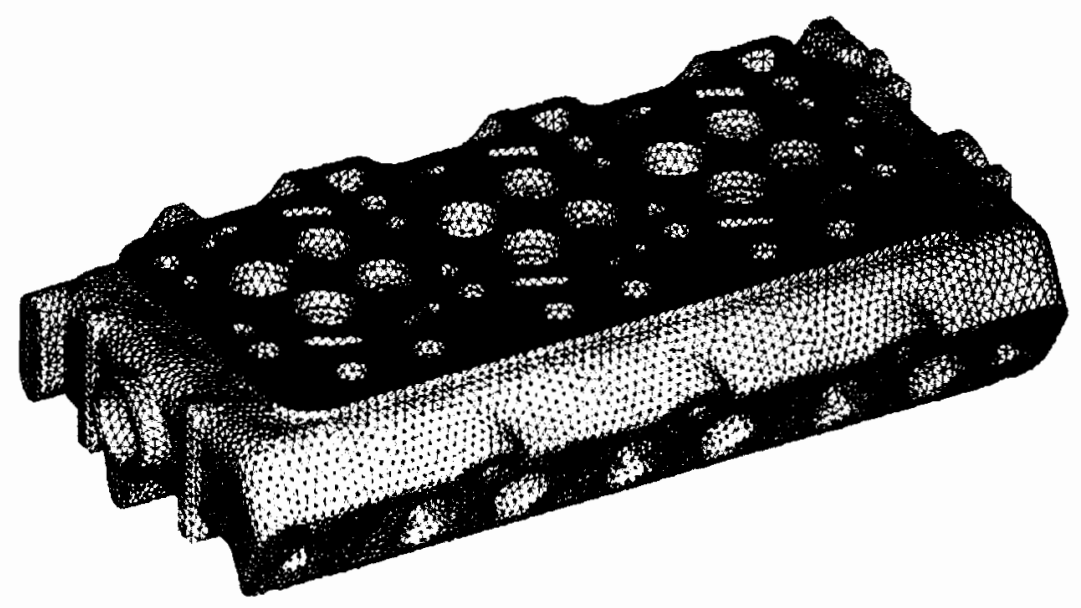

Figure 10: Cylinder Head FEA

Engine assembly and testing activities were initiated, and the first vehicle integration was begun using a Dodge Durango SUV. The first DELTA Gen 0 engine installed in a test cell is shown in Figure 11. 


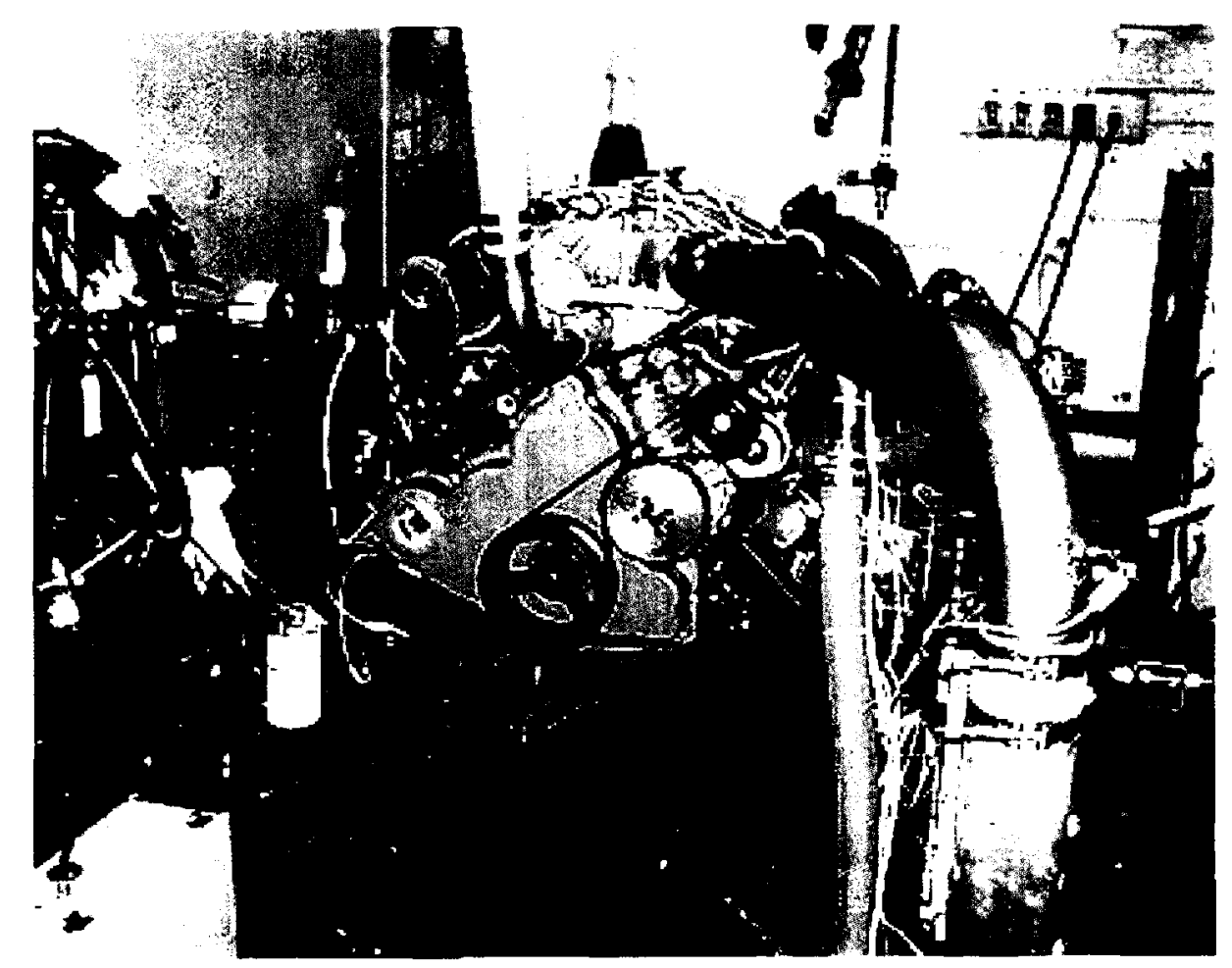

Figure 11: The First DELTA Gen 0 Engine Installed in a Test Cell

\section{Progress for the Period July - September 1998}

The Durango repower was completed in August furnishing an operational vehicle (Figure 12) Performance testing of the Durango was initiated and many improvements were identified and pursued. The vehicle was successfully demonstrated to the public and press.

A 5.9L gasoline $V-8$ engine was removed from the vehicle. Vehicle modifications were minimized; however, minor modifications were necessary to accommodate the diesel air intake system. The vehicle exhaust system was used as received, except for eliminating the muffler, which was replaced with an aftertreatment device that included a diesel particulate filter (DPF).

Existing engine mount locations were used, but the mounts were tuned to the diesel engine. Stock Chrysler accessories were reused, from the original 5.9L V-8 gasoline engine. These included: power steering pump, alternator and the air conditioning compressor. The water pump, fuel transfer pump and vacuum pump were components of the core DELTA diesel engine.

The vehicle was modified to a 2 -wheel drive, manual transmission configuration to avoid interferences with the 4-wheel drive version and due to issues of electronics to interface. 


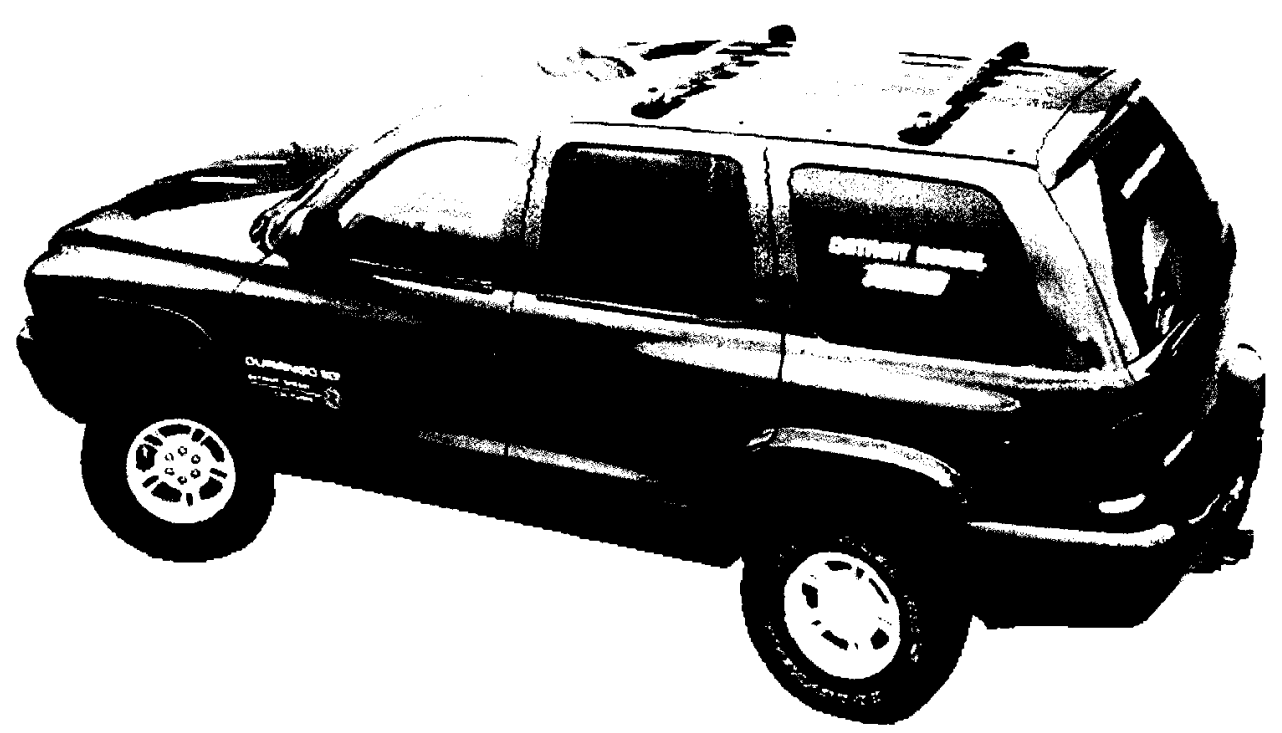

Figure 12: Durango Repowered with a DELTA Gen 0 Engine

During this period, a fuel consumption baseline was established and pilot injection enabled. The fuel consumption map in Figure 13 reports the results of this development effort. These results were very preliminary with further refinement and emissions development planned in the future.

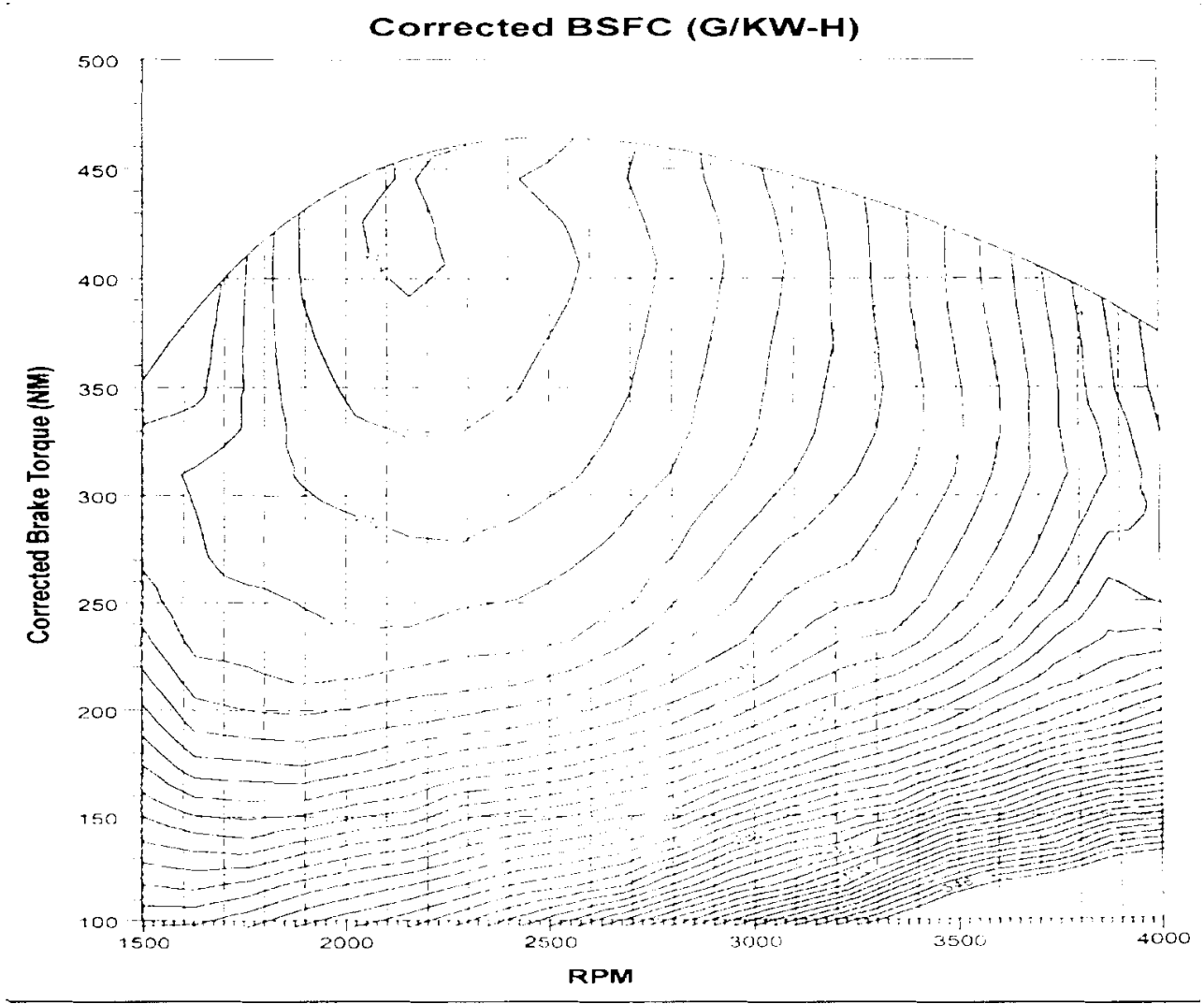

Figure 13: Preliminary Gen 0 Fuel Consumption Map 
The 4.0L V-6 DELTA-powered Durango (rated at $210 \mathrm{hp}$ ) yielded a significant improvement in fuel economy over the $5.9 \mathrm{~L} \mathrm{~V}$-8 gasoline engine (rated at $245 \mathrm{hp}$ ) as shown in Table 1 . This was accomplished at a small cost in $0-60 \mathrm{mph}$ acceleration. Combustion sound quality was improved substantially through use of the common rail fuel system in the DELTA-powered Durango.

Table 1 also compares the interior noise levels. Sound pressure measurements were made at the driver's ear position. The diesel was within two dBA of the stock gasoline engine.

Table 1: Durango Performance vs. Engine

\begin{tabular}{|c|c|c|} 
& Gasoline 5.9L V-8 & Diesel 4.0L V6 \\
\hline $\begin{array}{c}\text { Fuel Economy } \\
\text { (standard test route used by } \\
\text { DDC) }\end{array}$ & $12.5 \mathrm{mpg}$ & $21.8 \mathrm{mpg}$ \\
\hline $\begin{array}{c}\text { Acceleration } \\
\text { (0-60 mph time) }\end{array}$ & $12.6 \mathrm{sec}$. & $14.2 \mathrm{sec}$. \\
\hline $\begin{array}{c}\text { Interior Noise } \\
\text { (sound pressure @ driver's } \\
\text { ear @ idle) }\end{array}$ & $58 \mathrm{dBA}$ & $60 \mathrm{dBA}$ \\
\hline
\end{tabular}

Following the first Gen 0 Durango vehicle development tests, DDC initiated a series of engine improvements. These included electronic control upgrades, various hardware upgrades and manufacturing improvements. This laid a path for designing the series of Gen 0.5 engines, while completing the assembly of the four Gen 0 engines.

\section{Progress for the Period October - December 1998}

With some design improvements made as part of the Gen 0.5 phase, progress was made in procuring Gen 0.5 engine components.

The Gen 0 EGR system performance was investigated and emissions testing initiated. Different air system options were examined for additional EGR flow. Initial results showed less than expected maximum EGR rates, even with relatively high backpressures. At $2000 \mathrm{rpm}$ and $300 \mathrm{NM}$ ( $65 \%$ load), maximum EGR rates ranged from $8 \%$ at a turbine outlet pressure (TPO) of $2 \mathrm{kPa}$ to $10.5 \%$ at a TPO of $7 \mathrm{kPa}$ (EGR rates based on airflow measurements).

Additional improvements were made to the vehicle and engine to improve $\mathrm{NVH}$ and performance:

- Additional noise insulation features were added, including a belly pan with several iterations of foam thickness.

- New engine mounts were installed which reduced vibration levels in the passenger compartment. 
- Rail pressure and pilot shut-off speed were modified to improve the tone of the combustion noise at high speed and loads.

Following these improvements, the focus was turned to testing and refinement of the Durango in terms of performance and emissions as illustrated in Figure 14. Specifically, vehicle cold starting was explored and refined while a diesel oxidation catalyst was added to the vehicle.

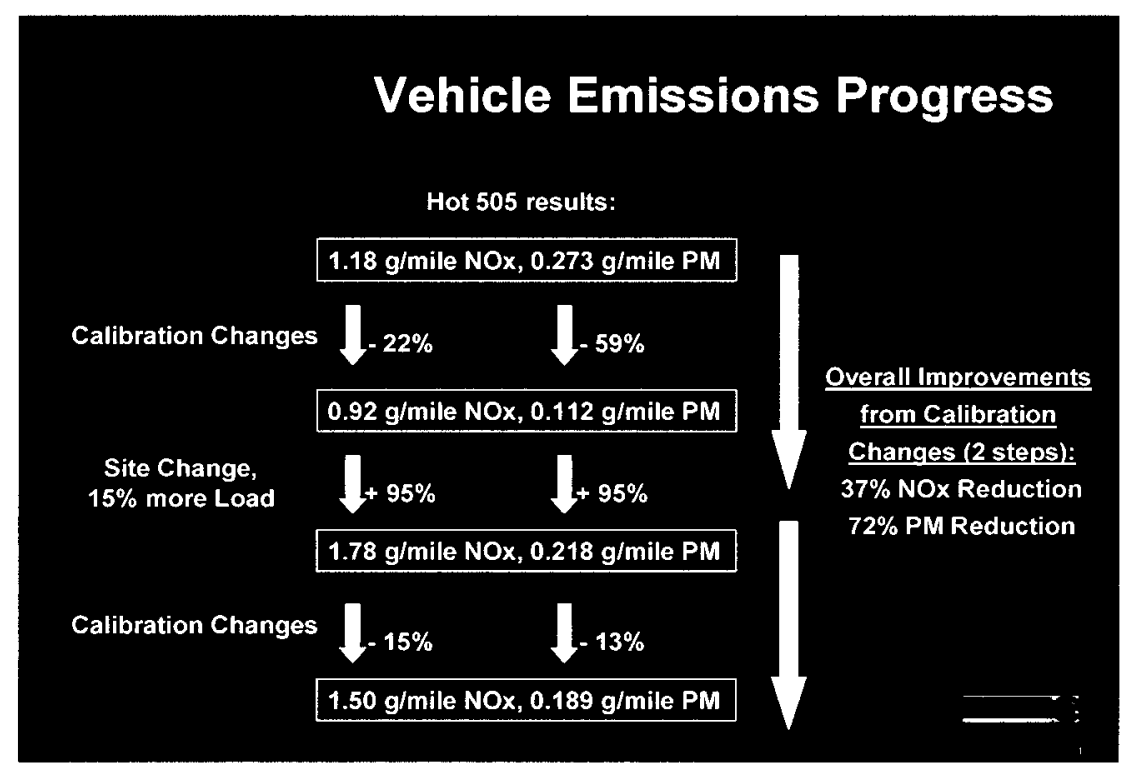

Figure 14: Vehicle Emissions Testing

\section{9}

\section{Progress for the Period January - March 1999}

In this first quarter of 1999 , Gen 0.5 block casting issues were investigated. The following changes were made to address problems

- Changed tooling by adding a core print on the water crossover core into the front core.

- Modified the core assembly to eliminate potential for core shift during transfer of the assembly to the drag mold.

- The water drain hole was moved to prevent thread break-through.

A Design of Experiment's injector tip test investigated the performance and emissions trade-off associated with four different VCO tip configurations and two levels of tip protrusion. Tips with two different hole diameters (flow rate varied by $5 \%$ ) and number (five or six) were used. Spray 
angle was held constant. The baseline (standard) tip had a higher flow rating and six holes Operating variables included engine speed, load, main injection timing, rail pressure and pilot injection activation, along with studies investigating injector and tip variants. The 5-hole lower flow injector tip with less tip protrusion had been selected as a configuration to test in the Durango vehicle in order to assess the emissions impact over the FTP cycle.

The Durango engine calibration was refined and a continuously regenerating particulate trap was installed. The following strategies to reduce NOx were implemented:

- During starting, no pilot injection should be present.

- At idle, the best timing is pilot injection 10 degrees before main injection, with main injection at TDC.

- At low load cruising conditions, lowest NOx was achieved with no pilot and low rail pressure.

- During high load accelerations, lowest NOx was achieved with pilot injection and high rail pressure.

These strategies required pilot injection to be enabled, and then setting the pilot quantity to zero in certain areas of the map. Acoustic attenuation of the DPF was sufficient to eliminate the need for additional muffling. Mass of the prototype DPF dictated frame mounting with flex connects for vibration isolation. The turbo-to-DPF exhaust pipe was insulated to maximize DPF inlet temperatures. Thermocouples were installed ahead of the DPF to monitor inlet gas temperature.

The expected $90 \%$ reduction in PM with the DPF was confirmed. The combination of the DPF and the timing moved the NOx/PM tradeoff curve significantly to the left. This represented a large step towards the ultra low emission levels targeted. The DPF lowered the $\mathrm{HC}$ and $\mathrm{CO}$ down to almost negligible levels.

Effort was also spent on designing a twin wastegated turbocharger option as shown in Figure 15. This included redesign of exhaust manifolds, and turbo oil supply and return tubes. The exhaust crossover pipe at the rear of the engine was eliminated with this configuration.

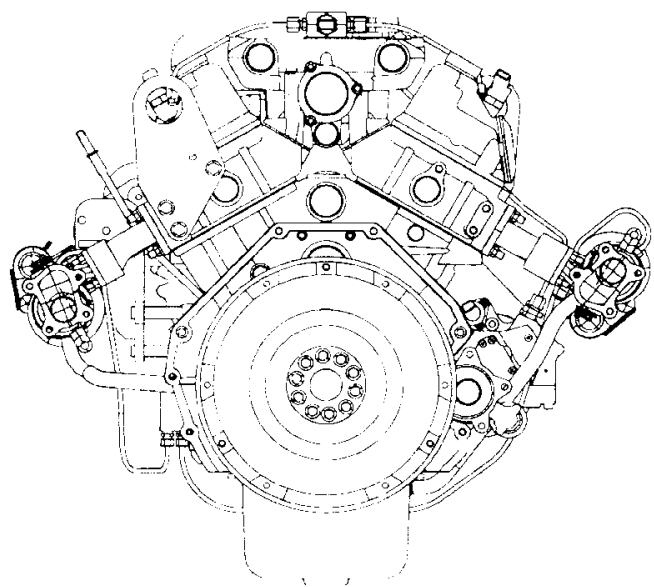

Figure 15: Twin VGT Gen 0 Configuration (Rear View of Engine) 


\section{Progress for the Period April - June 1999}

The Gen 0.5 Cylinder block casting, which included core modifications to eliminate thin wall condition, as well as risers added to eliminate porosity, was successfully poured. It was premachined and successfully passed leak check. Based on these results, the decision was made to proceed with the manufacture of cores and casting of additional blocks.

Performance testing of the twin wastegated turbochargers was completed. The notable performance difference was in the potential to drive EGR. Attempts at developing a full load curve with the hardware failed; the wastegates were incapable of bypassing enough energy to prevent turbo overspeeding at engine speeds above $2500 \mathrm{rpm}$.

Tests were conducted to validate the new internal timing wheel. The new timing wheel used a wide gap for the once-per-rev reference signal, as opposed to using a wide tooth as the reference signal. The engine successfully synchronized, started and ran at rated speed using the internal timing wheel. The signal from the internal sensor was acceptable.

Vehicle development concentrated on PM versus NOx studies with the DPF and addition of $\mathrm{NVH}$ improvements to the Durango. Figure 16 reveals results of interior vehicle noise tests.

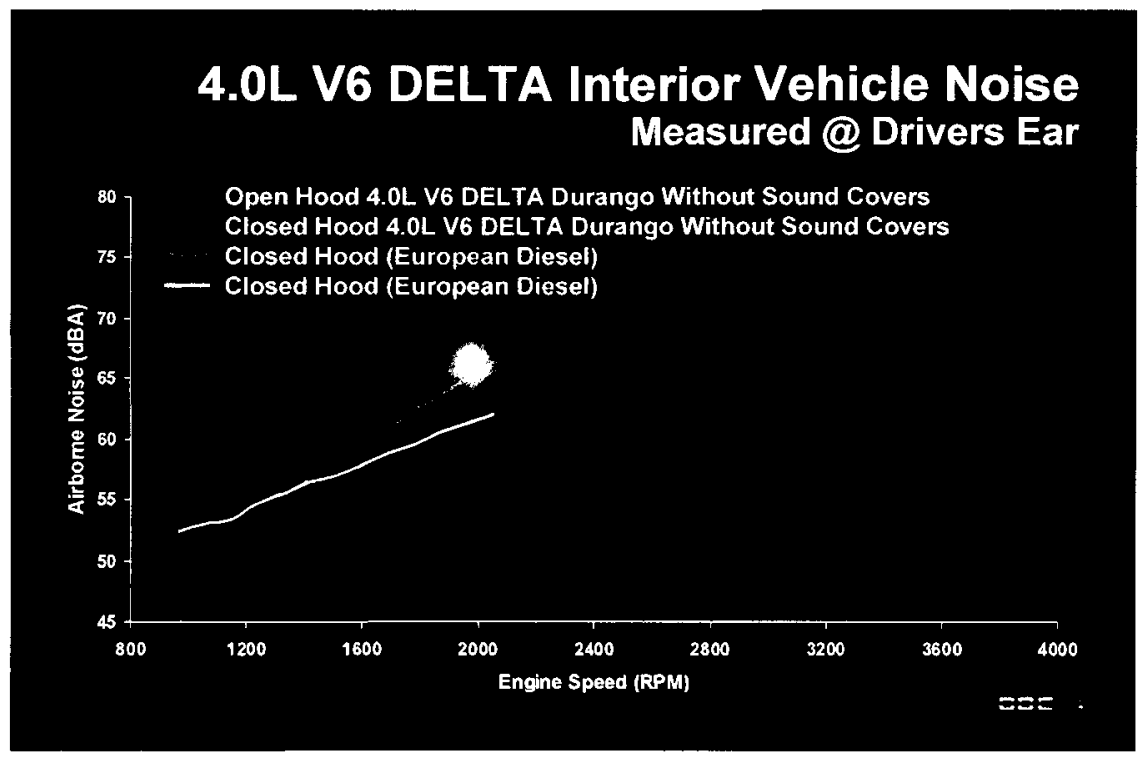

Figure 16: Durango Interior Noise Test Results

Although the Durango was generally perceived as having good NVH characteristics, some vehicle-engine interface-related issues were detected which confounded assessment of enginerelated noise. In order to isolate and correct the detected noises, the work performed included the following: 
- Underhood noise isolation: Additional insulation material was installed in the shifter boot and along the sides of the hood. An air inlet snorkel was installed on the air cleaner box to reduce the intake noise.

- Transmission gear rattle and driveline clunk reduction during moderate throttle tip-in-tip-out: A damper was installed on the drive shaft to correct this problem.

- Shut-down shake and after-shake reduction: The tuning included adjustment of the mount dampening level and gap, as well as rear transmission mount stiffness.

\section{Progress for the Period July - September 1999}

As analysis tasks progressed, the cooling system CFD study was completed during this period. The results are summarized here:

- The coolant flow was unevenly distributed. About $60 \%$ went to the right bank, $40 \%$ to the left bank.

- Flow to the EGR cooler was quite low, about 3.3\% of the total flow (which was part of the flow to the right bank) resulting in a low flow velocity in the EGR cooler.

- The rear cylinders in each bank received close to the per-cylinder average flow for their bank, indicating adequate coolant flow was delivered to the rear of the cylinder block.

- However, flow velocity was lower in the rear region of the block than in the front. For better cooling performance in the cylinder block, it was desirable to allocate more coolant flow to the rear cylinders by, for example, gradually increasing head gasket water passage hole sizes from front to rear.

- Over $90 \%$ of the coolant flow exited the block and entered the cylinder head from the exhaust side, creating a strong cross-flow pattern in the cylinder head. This enhanced the cooling effect on the exhaust side, but caused non-uniform cooling of the upper cylinder bore wall.

Based on the above conclusions, design enhancements were considered for Gen 1 in order to (1) balance coolant flow between the two banks, (2) improve coolant flow uniformity around each cylinder bore, (3) distribute more coolant flow to the rear cylinders and (4) increase coolant flow to the EGR cooler.

The effect of inertia weight on NOx, PM and fuel economy (MPG) was established. The observed trends were that NOx and PM increase in nearly linear direct proportion to inertia weight, while MPG decreased almost linearly as inertia weight increased.

During the USO6 aggressive driving cycle test that is included in Supplemental Federal Test Procedure (SFTP), the engine produced approximately $50 \%$ greater NOx and $150 \%$ greater PM as compared to the Hot 505

The four key structural concerns identified in DELTA Gen 0 engine were: 1) high cylinder block bulkhead stress, 2) low crankshaft fatigue safety factor, 3) low con rod fatigue safety factor and 
4) con rod bearing overlay fatigue due to high unit loading. Resolution of these concerns was paramount for meeting durability and reliability targets.

Other key drivers for Gen 1 redesign were cost and weight targets, maintaining acceptable NVH and maintaining capability of modularity with a $V-8$ derivative. Increasing bore spacing was likely to provide the best basis for resolving the four identified key structural concerns. The small increase in length was believed to be acceptable from vehicle packaging standpoint, while providing displacement growth potential. The key elements of the initial Gen 1 design proposal are outlined in Figure 17.

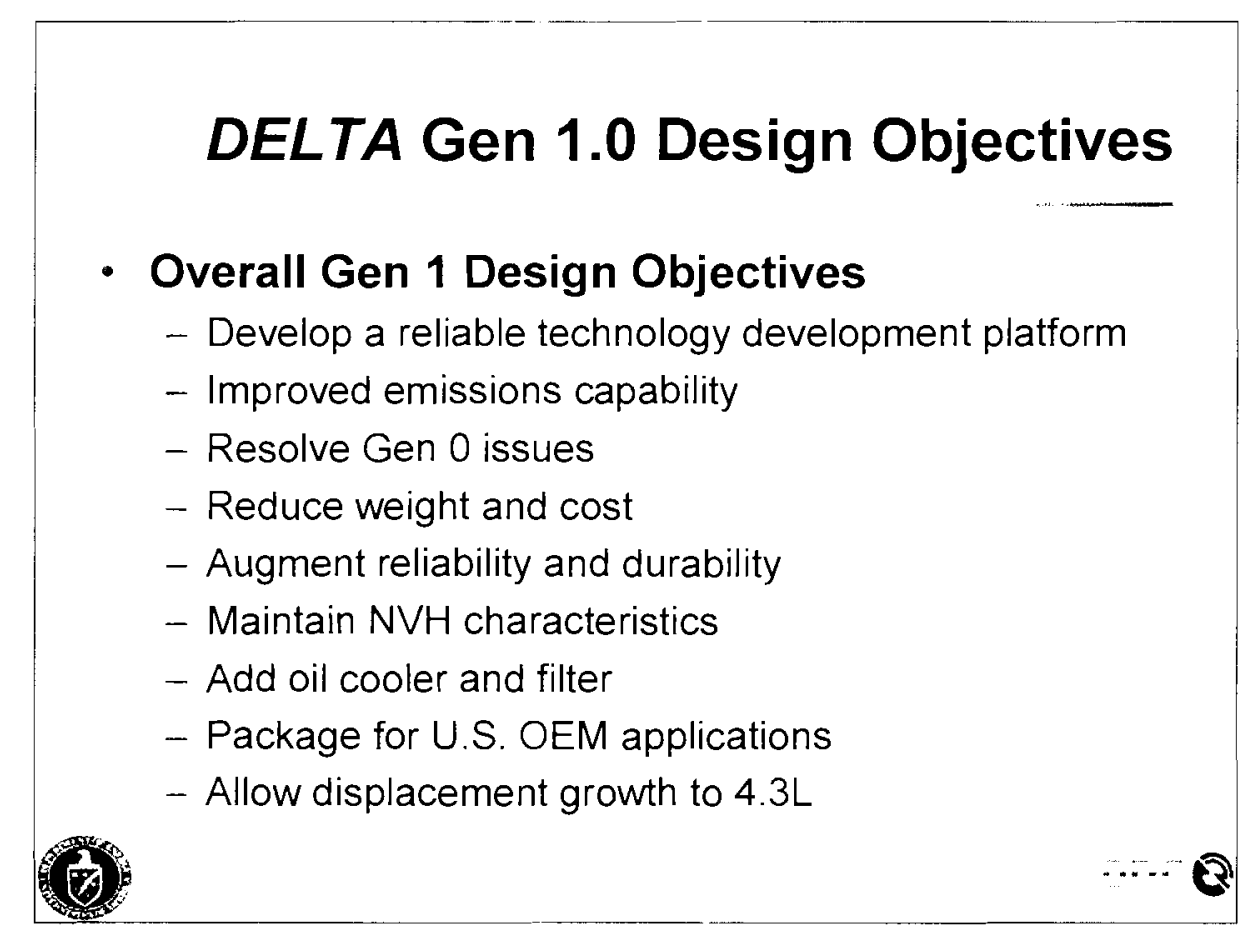

Figure 17: Gen 1 Design Initiated to Resolve Gen 0 Issues

\section{Progress for the Period October - December 1999}

A number of analysis tasks were performed to baseline the Gen 0 engine mathematical models. This included thermodynamic cycle simulation and exhaust manifold FEA. The primary conclusions from the exhaust manifold FEA were that longitudinal thermal expansion of the manifold exceeds the bolt-to-bolt hole clearance, causing warpage, and that the attaching bolts were too short to accommodate the required amount of stretch. The following recommendations were made:

- Increase the diameter of the manifold mounting bolt holes

- Increase the thickness of the manifold mounting flange 
- Use longer bolts, utilizing spacers as necessary in combination with thicker mounting flange

- Increase torque on the mounting bolts to increase clamp load

- Use high Si-Moly ductile iron in addition to the above if necessary (dictated by temperature level)

The capability of increasing power in the Durango was also studied, which led to an improved Gen 0 rating of $230 \mathrm{hp}, 375 \mathrm{ft}-\mathrm{lb}$, as shown in Figure 18.

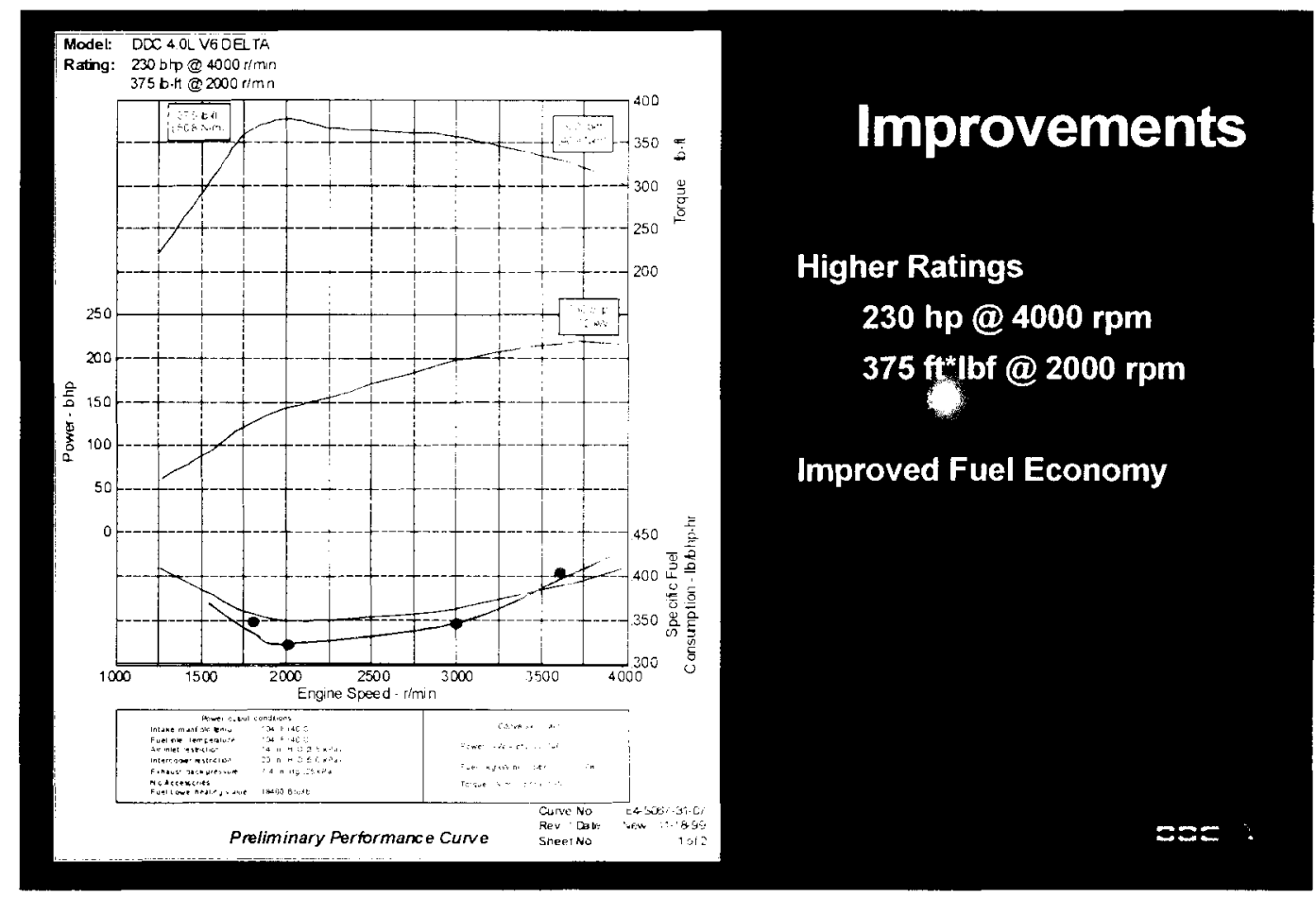

Figure 18: DELTA Improved Performance Curve

Gen 0.5 tests with higher rated DELTA engines have produced much better acceleration characteristics. A $5,950 \mathrm{lb}$ vehicle, equipped with a $230 \mathrm{hp} / 375 \mathrm{ft}-\mathrm{lbf}$ DELTA engine and a 4speed automatic transmission, achieved 8.5 -second, 0 to $60 \mathrm{mph}$ acceleration times.

Figure 19 depicts vehicle speed as a function of time. One curve represents a standard launch, which was subject to wastegated turbocharger lag. The second curve was achieved by launching the vehicle after applying load to the engine, using the torque converter and the vehicle brakes.

A total of six Gen 0.5 engines were assembled, including a durability engine, and Gen 0.7 procurement initiated. 


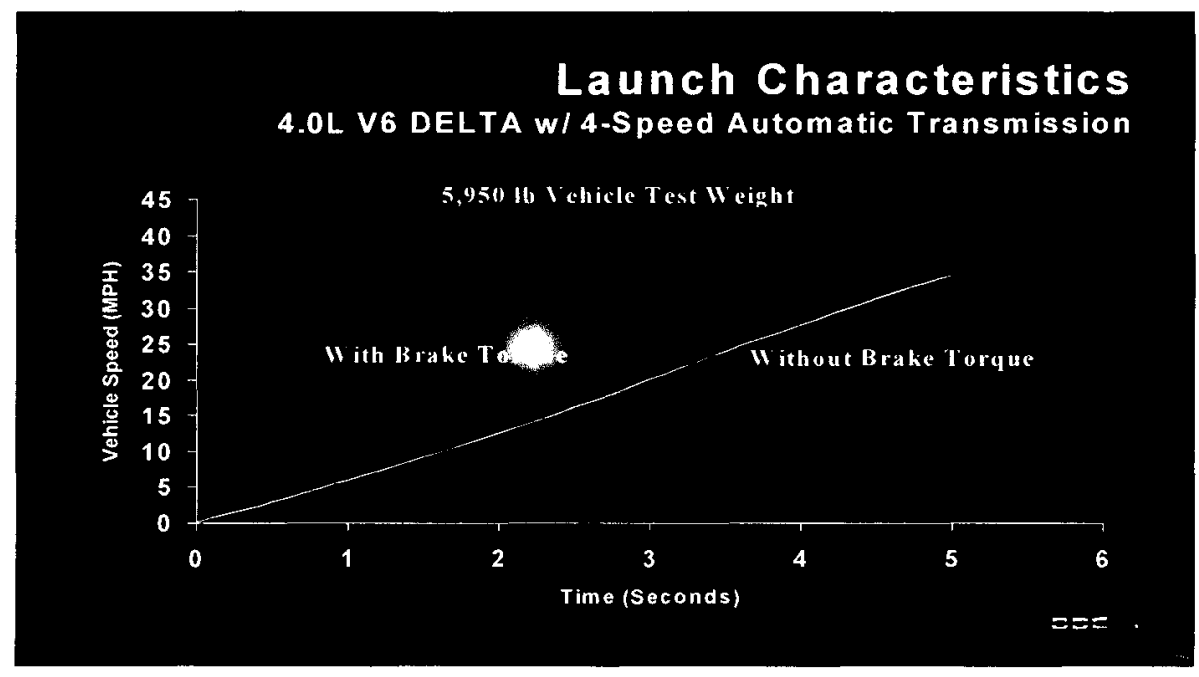

Figure 19: Gen 0.5 Launch Characteristics

\section{0}

\section{Progress for the Period January - June 2000}

\section{SAE Paper 2000-01-2197 [1] was presented}

On the development front, simulations and engine testing continued, as well as hardware procurement of Gen 0.7 configuration.

The Gen 1 design continued with the crankshaft, cylinder block and connecting rod as lead components. At a meeting with the crankshaft supplier, it was decided that some external balancing (in the vibration damper and flywheel or flexplate) needed to be considered for Gen 1 since the balancing approach used to-date was not feasible for production. Although not related to strength, the rod bearing bore diameter was also increased from $72 \mathrm{~mm}$ to $74 \mathrm{~mm}$. This change, along with the bearing journal length increase, was made to reduce propensity for bearing overlay fatigue, which was identified as a concern in Gen 0 . Progress was also evident in developing a twin variable geometry turbocharger option for Gen 0.7 .

\section{Progress for the Period July - September 2000}

The assembly of Gen 0.7 engines was initiated in July. Two engines were tested, one with a twin VGT configuration and the other with the single wastegated turbocharger. Steady-state performance and emissions development testing was conducted with the twin VGT turbocharger configuration. The basic open loop control strategy for vane position was developed. 
The basic Gen 1 design concept was completed with detailed design work continuing. For each major component and subsystem, design objectives were reviewed along with key analysis results. The general conclusions were as follows:

- The Gen 1 design approach was on target to meet all of the design objectives.

- The Gen 1 design permitted future displacement growth potential to $4.3 \mathrm{~L}$, while reducing weight and height as compared to Gen 0 .

Vehicle testing emphasis was on the non-FTP operating range. The twin VGT turbocharger configuration was tested, and the integrated twin VGT and EGR control strategies were developed.

The DELTA information was presented at the DEER workshop in San Diego, California. [2], [3]

\section{Progress for the Period October - December 2000}

The achievements for the final quarter of this year included resolving machining issues with Gen 0.7 blocks and finalizing the enhancements to the Gen 1 engine in several areas as indicated in Figure 20.

\section{DELTA Gen 1.0 Areas of Change}

- Block and bed plate

- Crankshaft and bearings

- HP fuel pump

- Cylinder head

- Air inlet housing

- Water pump

- Oil cooler and filter

- Mounting/OEM interface

- FEAD

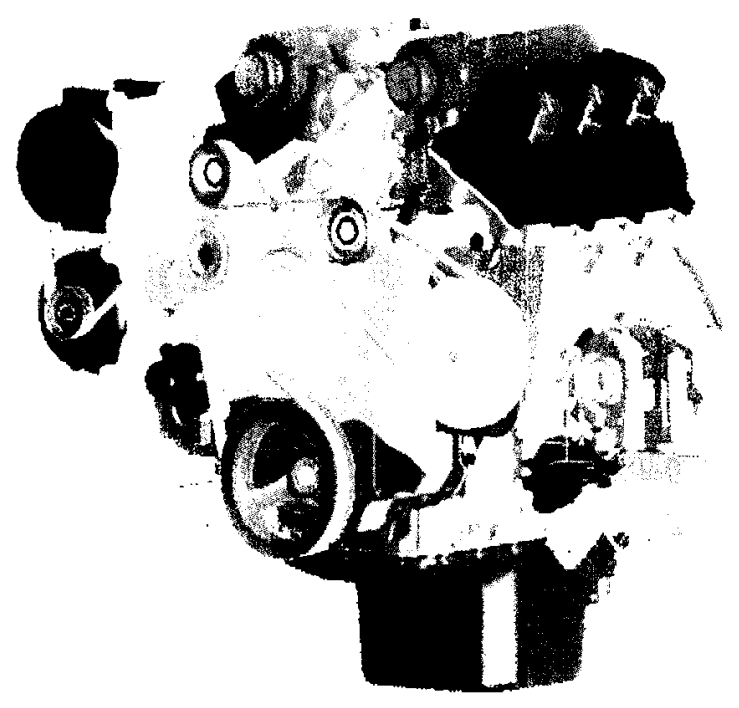

Figure 20: Gen 1 Areas of Change 
The Gen 1 design incorporated additional robustness to the mechanical engine components and addressed certain thermofluid enhancements in the engine cooling, lubrication and air systems, as well as enhanced fuel injection and combustion system designs. In addition, features for manufacturability and serviceability were maintained or improved.

The block, bedplate, crankshaft and cylinder head major structures were enhanced with selective added features (Figures 21-24). As an example, Figure 22 shows modifications to the coolant flow strategy, resulting in substantially uniform heat transfer to the engine coolant across all the engine's six cylinders.

\section{DELTA Gen 1 Block Improvements}

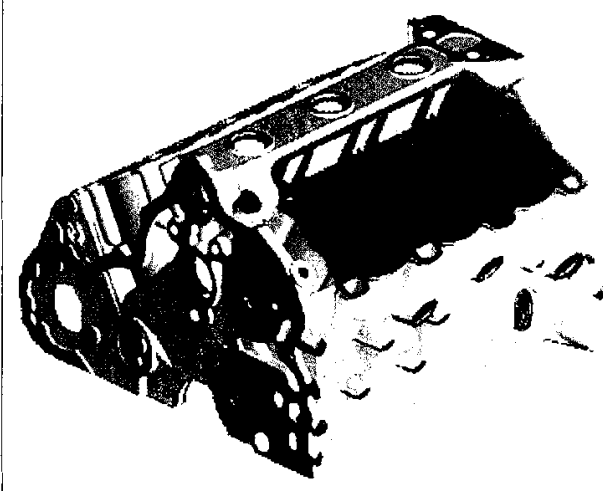

Balanced water jacket flow

Reduced vent window stress

Maintained Gen 0 weight

Increased bearing diameter

and width

Increased bore spacing

Figure 21: Gen 1 Block Improvements Over Gen 0 


\section{Gen 1 Cooling System Improvements}

- Balanced flow to each cylinder

- Organized flow around cylinders

- Adopted radial flow in cylinder head

- Increased EGR cooling

- Reduced system restriction

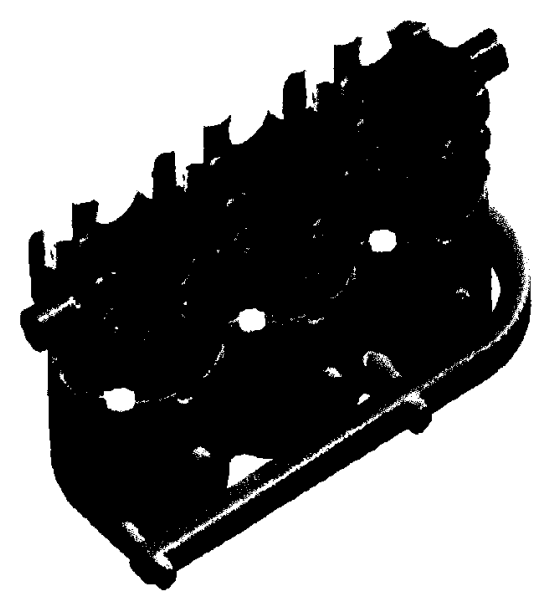

Figure 22: Gen 1 Cooling System Improvements Compared to Gen 0

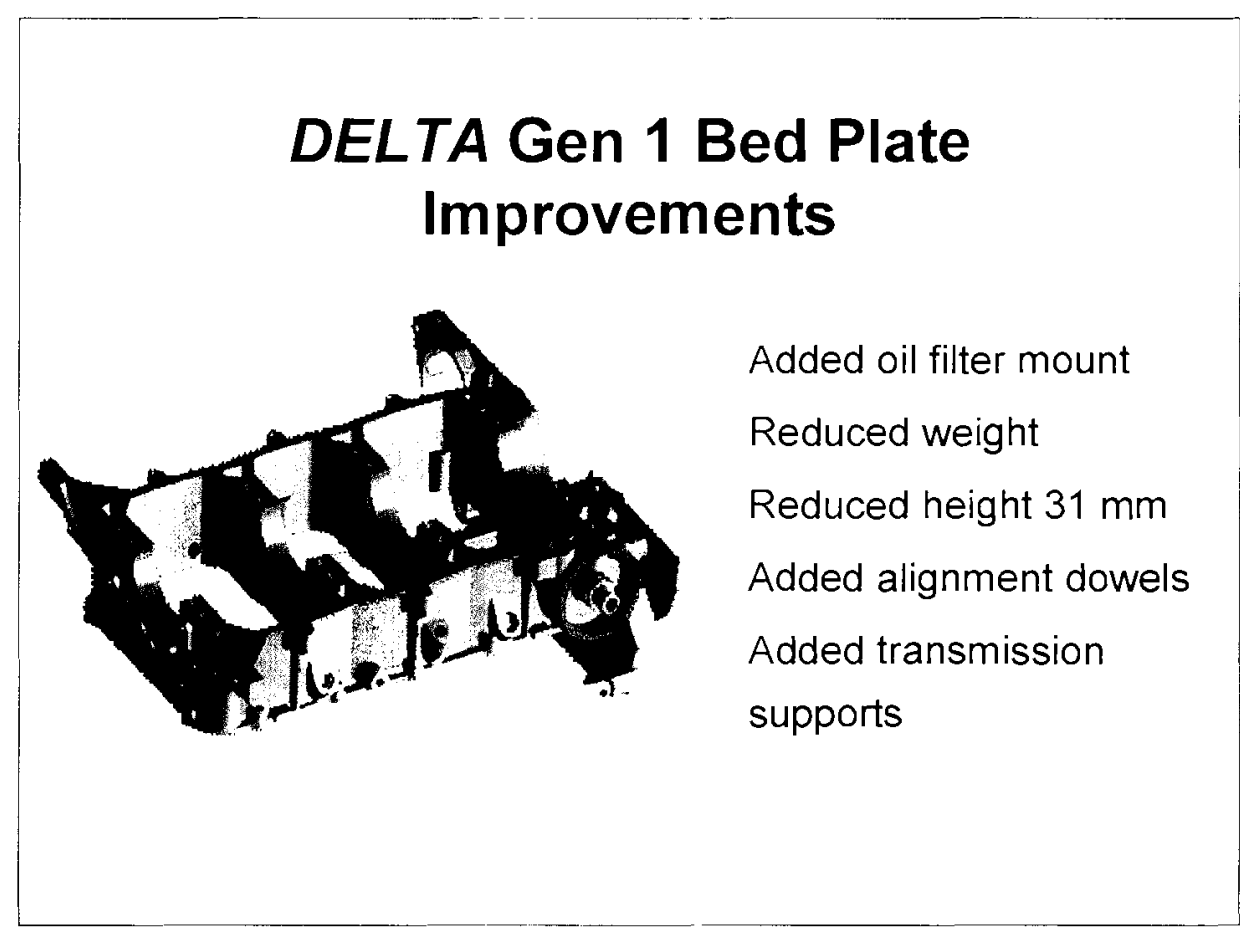

Figure 23: Gen 1 Bed Plate Improvements Compared to Gen 0 


\section{Gen 1 Cylinder Head Improvements}

- Removed water ports to AVI manifold, EGR passage, external core supports, and over $10 \mathrm{lbs}$ per head

- Added mid deck, injector sleeve, cast oil drains, and perimeter rocker cover bolts
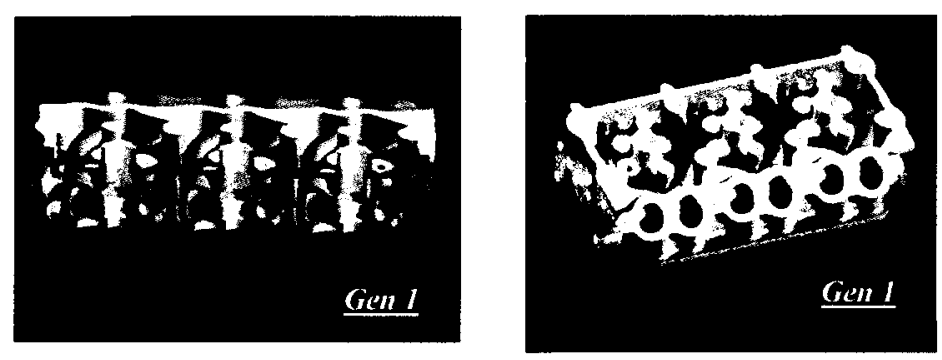

Figure 24: Gen 1 Cylinder Head Improvements Compared to Gen 0

An oil cooler was incorporated into the air inlet housing as part of the Gen 1 configuration, as shown in (Figure 25), along with improvements in the front engine accessory drive system to utilize a single belt drive (Figure 26).

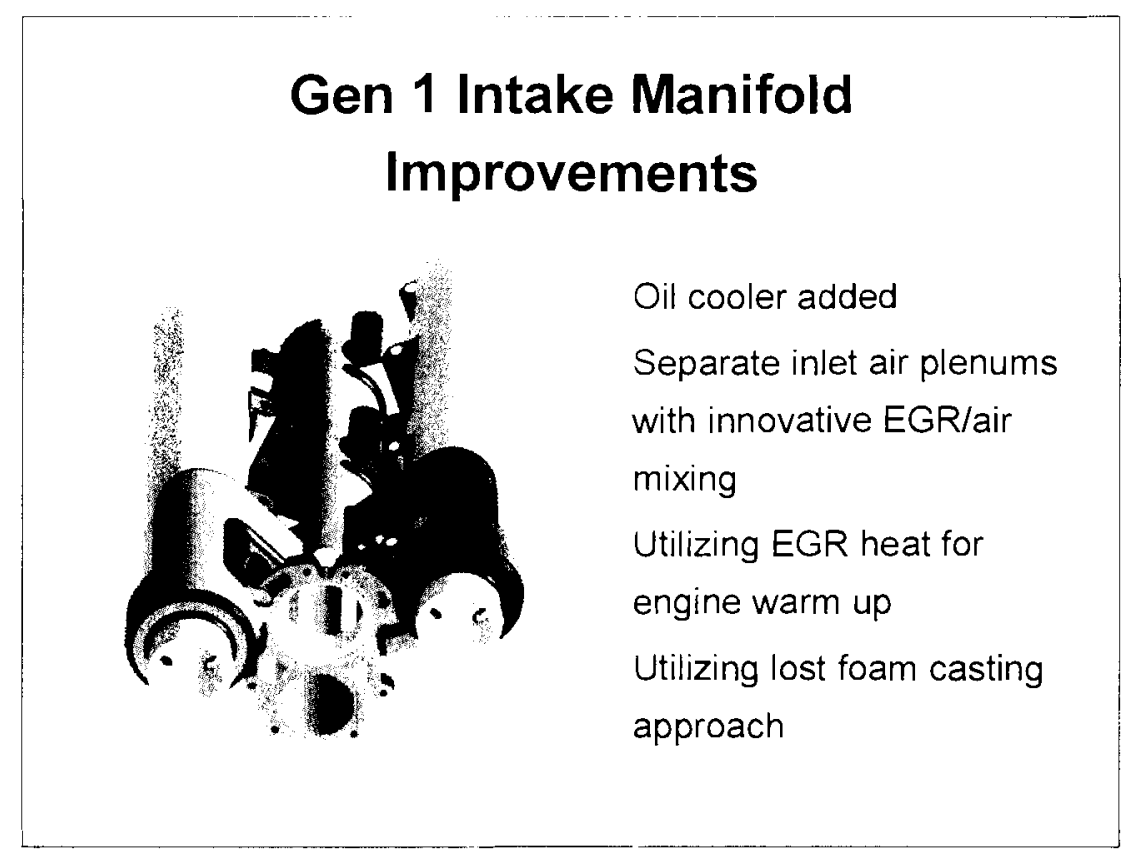

Figure 25: Improvements to the Intake Manifold over the Gen 0 Configuration 


\section{Gen 1 Front Engine Accessory Drives (FEAD)}

- Water pump mounted over crankshaft

- Water pump drives radiator fan

- Packages in U.S OEM engine compartment

- Single belt

- Automatic tensioner

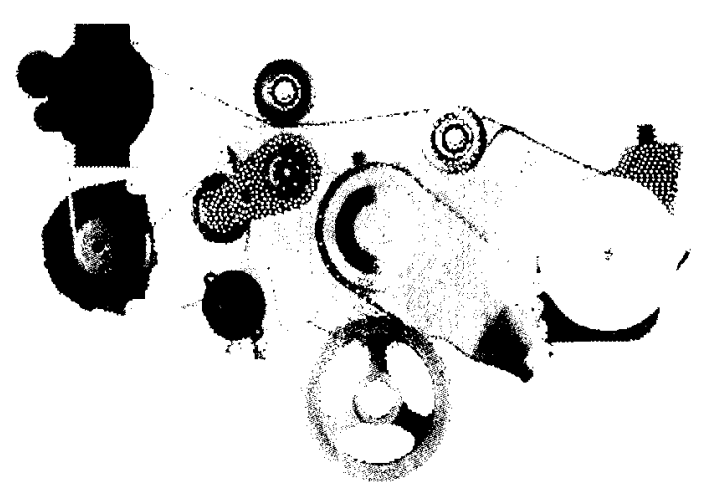

Figure 26: Gen 1 FEAD System with Single Belt

\section{1}

Progress for the Period January - March 2001

Figure 27 shows the DELTA design evolution. 


\section{DELTA Design Evolution}

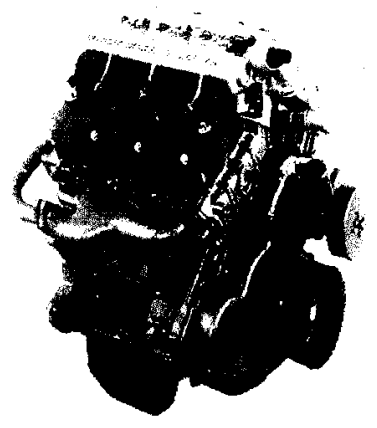

$\underline{\operatorname{Gen} 0}$

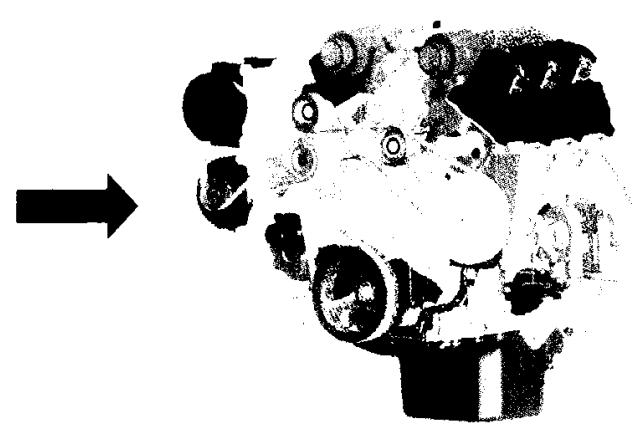

$\underline{\text { Gen } 1}$

Figure 27: Gen 1 Design Completed

The combustion development reviewed results of KIVA modeling for the effect of injector tip variants (Figure 28), engine performance mapping (Figure 29-30), and air system and EGR system simulation analysis (Figure 31 ).

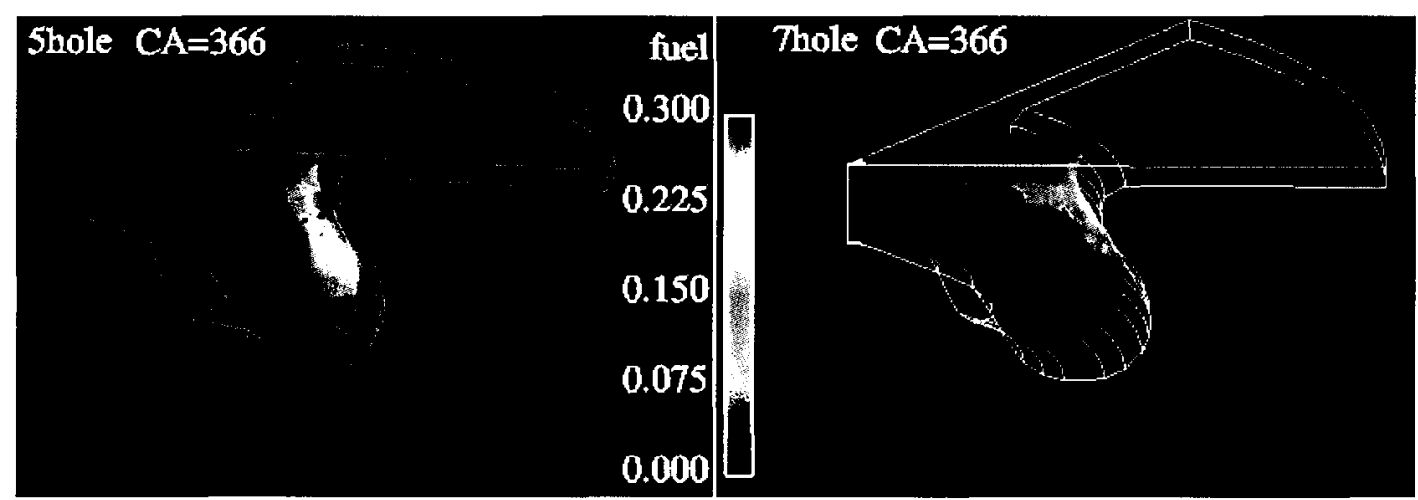

Figure 28: KIVA Modeling of Injector Tip Combustion Effect 


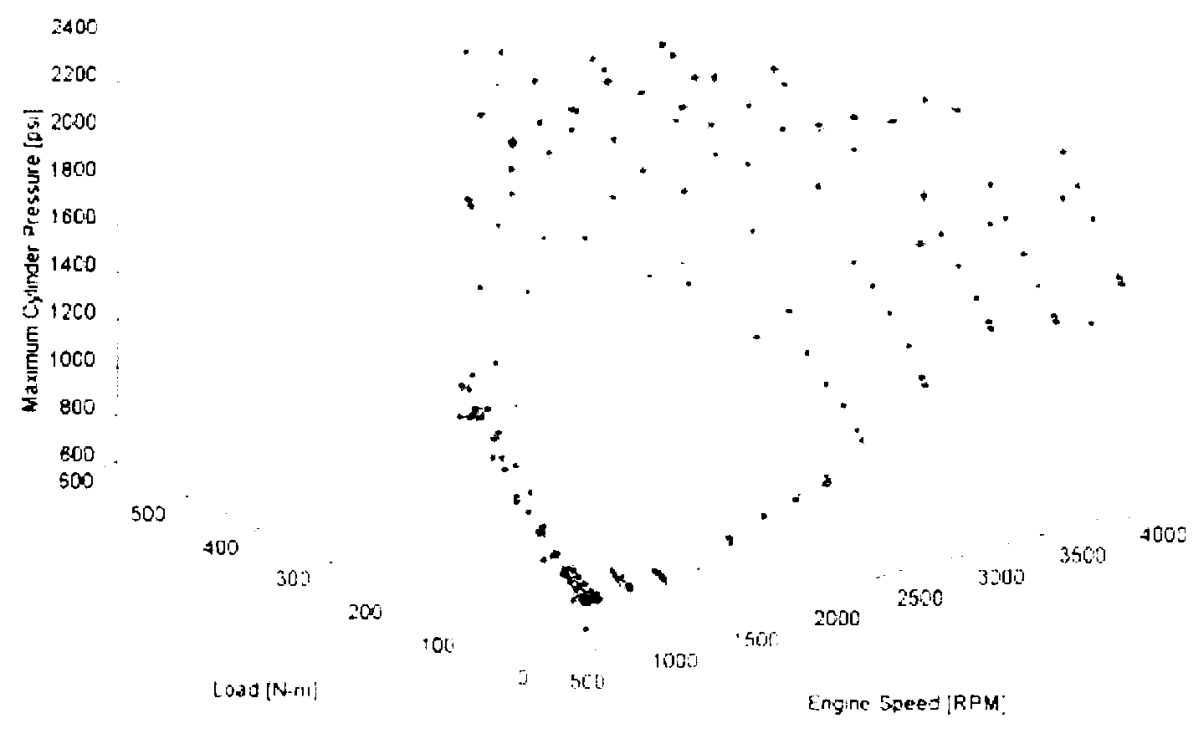

Figure 29: Gen 0.7 Cylinder Pressure vs. Speed/Load

I.maus: Maniegate-deratue

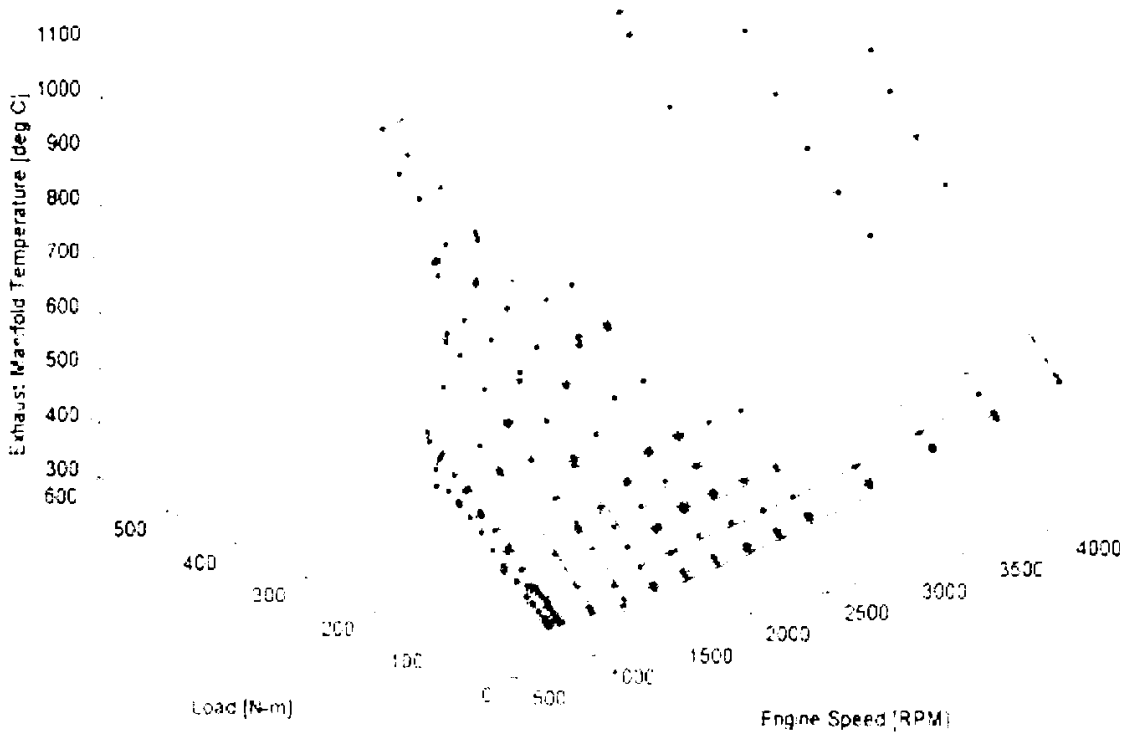

Figure 30: Gen 0.7 Exhaust Temperature vs. Speed/Load 


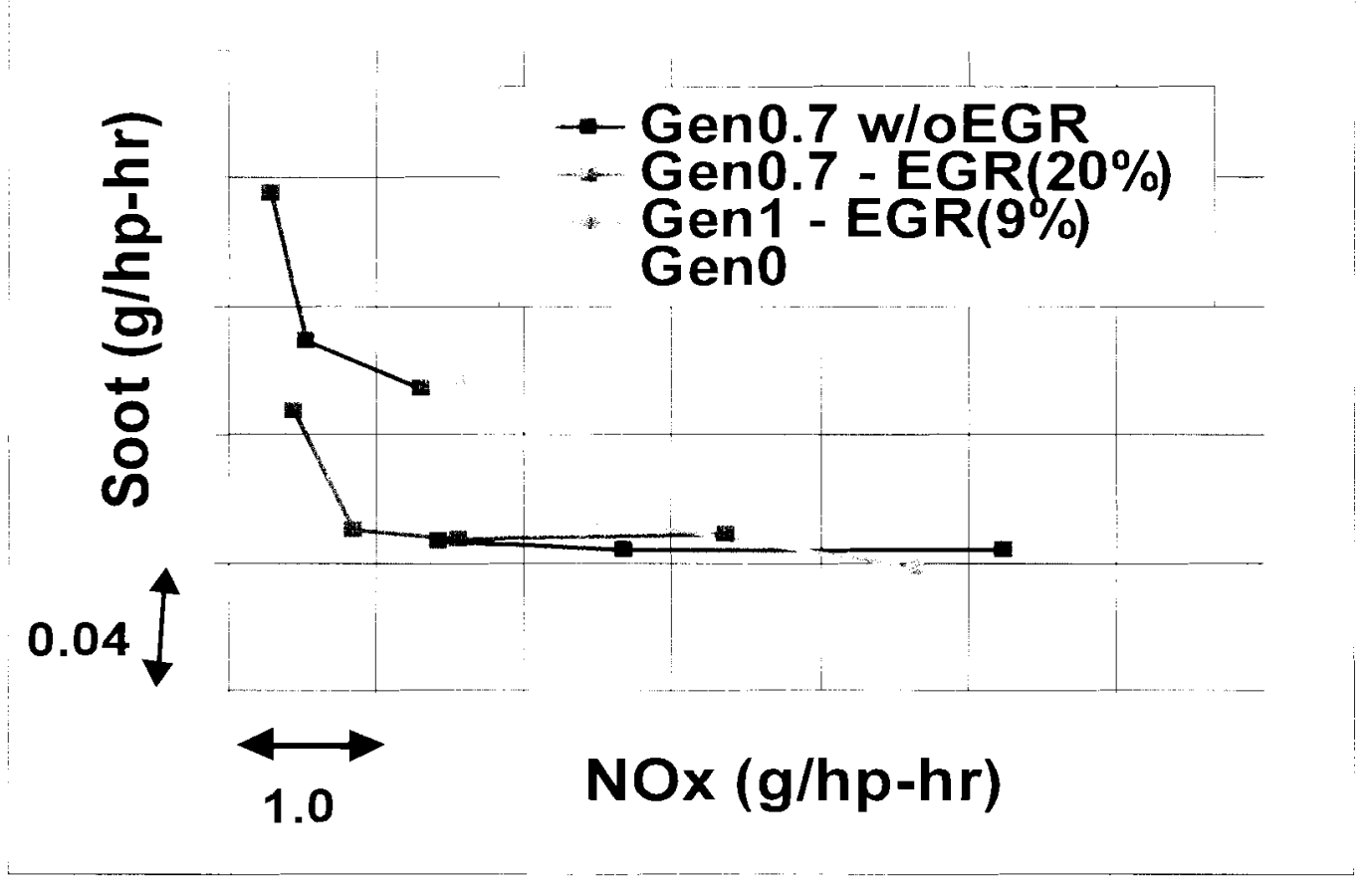

Figure 31: DELTA EGR and Air System Analysis

Reassessments of the reliability and durability development plan and of potential manufacturing scenarios were carried out.

\section{Progress for the Period April - June 2001}

Casting and machining tooling for the Gen 1 block. head and bedplate was completed and their creation initiated. The majority of Gen 1 components were received, inspected and inventoried.

The creation of a Gen 1 engine assembly manual, engine instrumentation manual and assembly instruction drawings were all prepared. The Assembly Manual defined the assembly process, parts needed (Bill of Material), torque specifications, sealant specifications and all other relevant information to allow the correct assembly of a Gen 1 DELTA engine.

The instrumentation manual served as a method to standardize the location and type of data measurements for the Gen 1 program. This allowed engines to be assembled with holes in place for thermocouples, pressure transducers and other necessary instrumentation. It also ensured that data measurements were consistent from engine to engine, both in test cells and vehicles.

Examples from the assembly manual and instrumentation manual are shown in Figures 32 and 33 , respectively. 


\section{Cylinder Block Setup}

The Gen 1 engine block/bedplate will be received as an assembly with camshaft bushings, balance shaft bushings, numerous cup plugs, pipe plugs and dowels installed. The following table lists the parts that are included in the X40281001 cylinder block assembly:

\begin{tabular}{|c|l|c|}
\hline $\begin{array}{c}\text { Part } \\
\text { Number }\end{array}$ & \multicolumn{1}{|c|}{$\begin{array}{c}\text { Description } \\
\text { X40281002 }\end{array}$} & CYLINDER BLOCK (MACHINED) -DELTA \\
\hline 05139997 & PLUG CUP .887 DIA STNLS & 1 \\
\hline 05132410 & PLUG CUP 1.645 STNLS & 2 \\
\hline 23511572 & PLUG PIPE 1/2 NPTF SQ SOC SCOTCH GRIP & 1 \\
\hline 05103045 & PIN DWL 312 X.38 LG TAPERED STL PL & 2 \\
\hline X40281003 & BOLT M12 1.5X115 (MAIN BEARING) -DELTA & 16 \\
\hline X40281004 & BEDPLATE (MACHINED) -DELTA & 1 \\
\hline X40281352 & DOWEL (HOLLOW 15.9 X 13.0) -DELTA & 8 \\
\hline 08924517 & PLUG PIPE 3/8-18 7/8 TAPER SQ SOC STL ZI & 2 \\
\hline 08923847 & PLUG PIPE 1/4 SQ SOC STL CTD & 4 \\
\hline 05130992 & PLUG CUP 1.788 DIA STEEL & 1 \\
\hline 05144559 & PLUG CUP 2.263 DIA STNLS & 1 \\
\hline 05197146 & PLUG CUP 1.136 STNLS & 8 \\
\hline 11504822 & BOLT M8 1.25 X 30.0 LG FLG HEX 10.9 & 8 \\
\hline 09427695 & PLUG CUP 3/4 & 2 \\
\hline X40281151 & BUSHING CAMSHAFT (FRONT \& REAR) -DELTA & 2 \\
\hline X40281152 & BUSHING CAMSHAFT (CENTER) -DELTA & 2 \\
\hline X40281108 & BUSHING - BALANCE SHAFT (FRONT \& REAR) - & 2 \\
\hline X40281109 & BUSHING - BALANCE SHAFT (CENTER) -DELTA & 2 \\
\hline
\end{tabular}

\section{a. Install Block/Head Alignment Dowels}

Mount the block/bedplate assembly onto an engine turnover stand with the top of the block facing upwards. Install 4 cylinder block-to-head hollow dowels X40280163

\section{b. Disassemble Block/Bedplate}

Rotate the assembly until the bottom of the bedplate is facing upwards.

Remove the (8) 11504822 perimeter bolts first, followed by the (16)

X40281003 main bearing bolts. Remove the bedplate and place it on a flat surface with bearing bores facing upwards.

Figure 32: Gen 1 Engine Assembly Manual Excerpt 


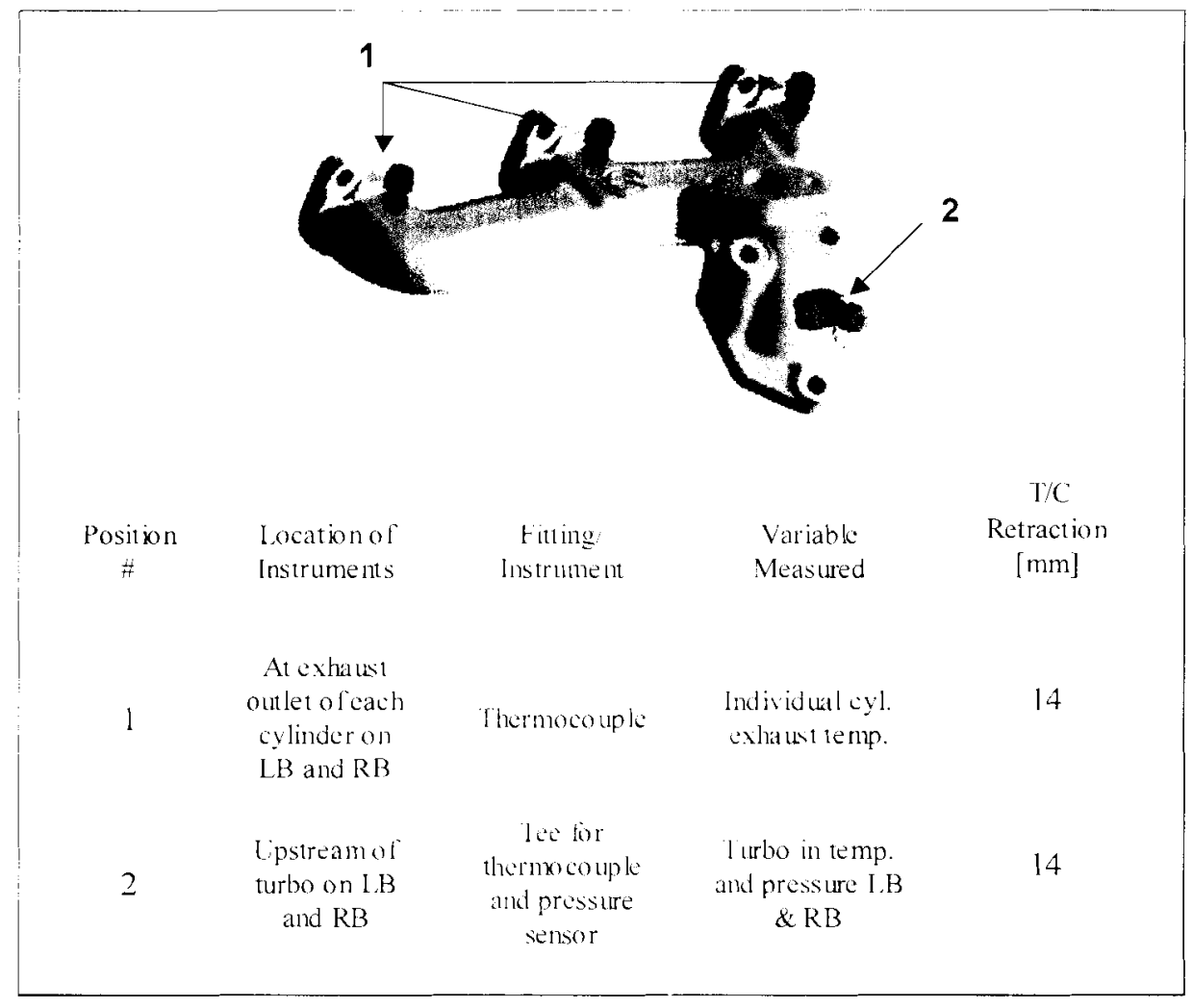

Figure 33: Gen 1 Engine Instrumentation Manual Excerpt

A Gen 0.7 engine was assembled and started operation on an endurance test cycle that combined FTP and US06 cycles (Figure 34).

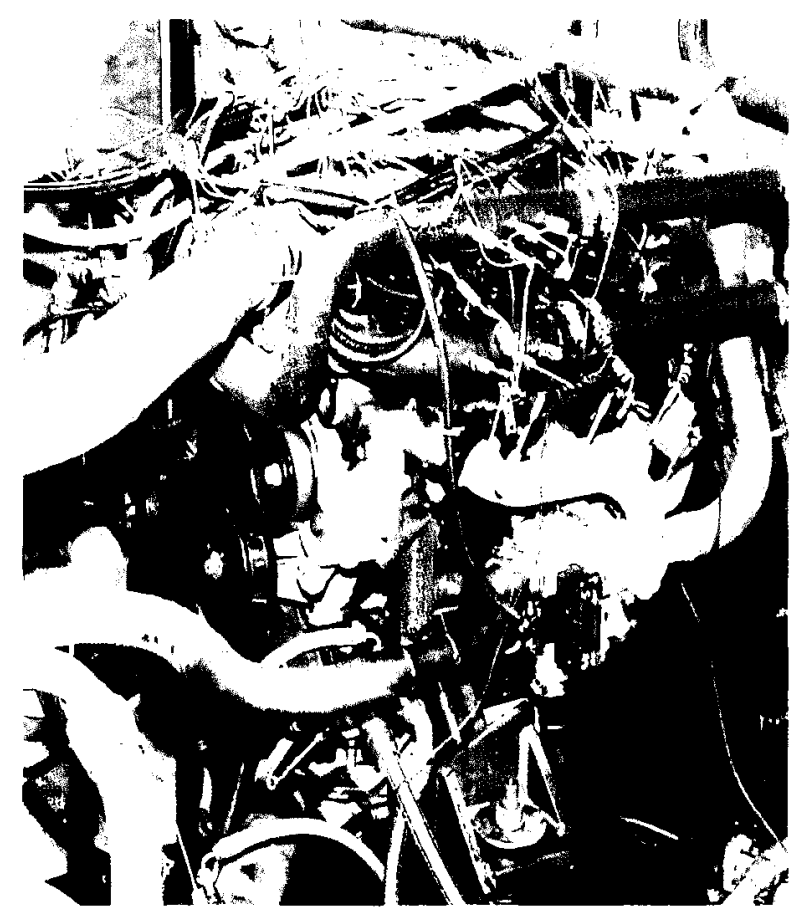

Figure 34: Gen 0.7 Durability Engine 
SAE Paper 2001-01-2062 covered an update on the technological achievements on the DELTA Gen 0 engine and the new Gen 1 engine design. [4] 


\section{REFERENCES}

1. Hakim, N.S., Freese, C.E., Miller, S.P., "The Detroit Diesel DELTA Engine for Light Trucks and Sport Utility Vehicles - Year 2000 Update", SAE Paper 2000-1-2197, SAE Government/Industry Meeting, Washington, DC, June 2000

2. Freese, C.E., Hakim, N.S., Redon, F., Zhang, H., "Light Duty Truck Aftertreatment Experience and Challenges", 6th Diesel Engine Emissions Reduction (DEER) Workshop, San Diego, California, August 2000

3. Bolton, B., Zhang, H., "Selection of Light Duty Truck Engine Arie Systems and Turbochargers Using Virtual Lab Tests", 6th Diesel Engine Emissions Reduction (DEER) Workshop, San Diego, California, August 2000

4. Hakim, N.S., Bolton. B., SAE Paper 2001-01-2062, "The Detroit Diesel DELTA Engine Recent Technological Achievements", 2001 SAE Government//ndustry Meeting, Washington, DC, May 2001. 